\title{
Ortaokul Öğrencileri İçin Eleştirel Düşünme Eğilimi Ölçeği’nin Geliştirilmesi: Geçerlik ve Güvenirlik Çalışması *
}

\author{
Seyhan YILDIRIM DÖNER ${ }^{* *}$ Sezgin DEMIR***
}

- Geliş Tarihi: 09.11.2020 • Kabul Tarihi: 17.06.2021• Çevrimiçi Yayın Tarihi: 17.06.2021

\section{$\ddot{O} z$}

Eleştirel düşünme eğilimi; bireylerin analiz, değerlendirme, yorumlama, tartışma gibi eleştirel düşünme kapsamında olan becerileri kullanmaya olan yönelimlerini ifade eder. Eleştirel düşünme eğilimi, eleştirel düşünme becerilerinin ve eleştirel düşünmenin etkilediği diğer becerilerin kullanımında ve gelişiminde önemli bir rol oynar. Bu araştırmanın amacı, ortaokul 5, 6, 7 ve 8. sınıf öğrencilerine yönelik (9-14 yaş arası) geçerli ve güvenilir bir Eleştirel Düşünme Eğilimi Ölçeği geliştirmektir. Açımlayıcı faktör analizi, test-tekrar test ve doğrulayıcı faktör analizi için her seferinde basit seçkisiz örnekleme yöntemi ile farklı bir örneklem grubu seçilmiştir. Elde edilen veriler üzerinden gerçekleştirilen güvenirlik analizlerinde Cronbach's Alpha değeri .87, SpearmanBrown ve Guttman Split-Half değeri .81 olarak tespit edilmiş ve ölçeğin oldukça güvenilir olduğu bulgusuna ulaşılmıştır. Ölçeğin test-tekrar test uygulamasında da iç tutarlılığa sahip olduğu bulgusuna ulaşılmıştır. İç tutarlılık katsayısının .75 olması test-tekrar test sonucunda ölçeğin tutarlılığının yüksek olduğunu göstermektedir. Açımlayıcı faktör analizi sonucunda \%42.94 toplam varyans değerine sahip ölçeğin 21 maddelik üç faktörlü ölçek yapısı, doğrulayıcı faktör analizi ile doğrulanmıştır $\left(\mathrm{X}^{2}=345.18, \mathrm{sd}=184 \mathrm{RMSEA}=.042, \mathrm{NFI}=.97, \mathrm{NNFI}=.98, \mathrm{CFI}=.99, \mathrm{GFI}=.88\right.$, $\mathrm{AGFI}=.85, \mathrm{SRMR}=.059$ ). Ölçeğin yapı güvenirliğinin .93 olarak hesaplanması ile ölçeğin yeterli düzeyde güvenilir olduğuna kanaat getirilmiştir. Araştırma sonucunda alan yazına 21 maddeli ve üç boyutlu olan, geçerli ve güvenilir likert tipi bir ölçeğin kazandırıldığı ifade edilebilir.

Anahtar sözcükler: eleştirel düşünme eğilimi, ortaokul öğrencileri, ölçek, geçerlik, güvenirlik.

Atıf:

Yıldırım Döner, S. ve Demir, S. (2022). Ortaokul öğrencileri için eleştirel düşünme eğilimi ölçeği'nin geliştirilmesi: Geçerlik ve güvenirlik çalışması. Pamukkale Üniversitesi Eğitim Fakültesi Dergisi, 54, 99-129.doi:10.9779.pauefd.823427

\footnotetext{
* Bu çalışma, “Ortaokul Öğrencilerinin Eleştirel Düşünme Eğilimleri ile Okuma Becerileri Arasındaki İlişki” adlı yüksek lisans tezinden hareketle oluşturulmuştur.

** Bilim Uzman1, Frat Üniversitesi, seyhanyldrm08@gmail.com, ORCID: 0000-0002-6778-4925

*** Doç. Dr., Fırat Üniversitesi Eğitim Fakültesi Türkçe Eğitimi Bölümü, sezgin.demir@ firat.edu.tr, ORCID: 0000-00020466-2218
} 


\section{Giriş}

Düşünme; devingen bir şekilde gelişen, değişen ve öğretilebilen bir beceridir. Düşünme süreci; başlangıcı olmayan ya da başlangıç zamanı belli olmayan, genellikle odaklanmayla başlayıp ilişkilendirmeyle sonlandırılması gereken bir süreçtir (Akarsu, 2019). Düşünmenin kendine özgü beceri alanları vardır. Costa (2001'den akt. Dilekli, 2019), düşünme becerilerini 4 temel başlıkta toplamıştır: eleştirel düşünme, problem çözme, karar verme, yaratıcı düşünme. Eleştirel düşünme; tanımlama, analiz etme, değerlendirme, yorumlama gibi pek çok zihinsel süreç ve aktivite sonucunda gerçekleşen bir düşünmedir. Ennis (1986'dan akt. Kurnaz, 2007), eleştirel düşünme kavramını bireyin yaptıkları ve inandıklarıyla ilgili karar verme sürecinde akla uygun ve derinlemesine düşünmesi olarak tanımlamıştır. Bloom (1956'dan akt. Fahim ve Eslamdoost, 2014); eleştirel düşünmenin Bloom Taksonomisi'ndeki aşamalarda bulunan tüm beceriler için gerekli olduğunu ve özellikle analiz, sentez ve değerlendirmenin genellikle eleştirel düşünmeye yönelik olduğunu bildirmiştir. Eleştirel düşünme; bireyin kendi düşünce süreçlerinin bilincinde olduğu, öğrendikleri doğrultusunda gerçekleşen olayları anlamlandırdığı ve bunu yapmayı kendisine amaç edindiği aktif bir zihinsel süreçtir (Cüceloğlu, 2001). Kişinin kendi düşüncelerinin ve görüş yanlılıklarının farkında olması, karşısına çıkan durumlar ve sorunlara çoklu bakış açısı ile bakabilmesi eleştirel düşünmenin önemli unsurlarıdır (Kökdemir, 2012).

Eleştirel düşünme kavramının iki temel boyutu vardır: beceri ve eğilim (Halpern, 1993, Facione, 1990, s. 3). Eğilim; bir alana, duruma ya da davranışa karş1 duyulan istek, onu yapmaya yönelik yatkınlık ve aynı zamanda mevcut becerileri kullanma yönelimi olarak tanımlanır (Facione, Giancarlo, Facione ve Gainen, 1995). Eğilimler, becerilerle ilişkilidir ve becerilerin kullanılmasında öncülük eder (Perkins, Jay ve Tishman, 1993). Eleştirel düşünme eğilimi, eleştirel düşünmeye ve eleştirel düşünme becerilerini kullanmaya yönelik gerçekleşen yönelimdir. Eleştirel düşünme becerilerini kullanmak için eleştirel düşünmeye yönelik bir eğilimin de olması gereklidir (Facione, Giancarlo, Facione ve Gainen, 1995). Pek çok araştırmacı, eleştirel düşünme eğilimine sahip olunduğu zaman var olan eleştirel düşünme becerilerinin kullanılabileceğini savunur (Halpern, 1998; Walker, 2003; Zhang, 2003). Sahip olunan beceri, eğilim olmadığı zaman kullanılamayacağ1 için körelir. Bu nedenle beceriyi tek başına öğretmenin yeterli olmayacağı, önemli olanın eğilim oluşturarak beceriyi kullanmaya yönelik istek duyulmasını sağlamak olduğu ifade edilmiştir (Halpern, 

eğilimini 7 karakteristik özelliğe ayırmıştır:

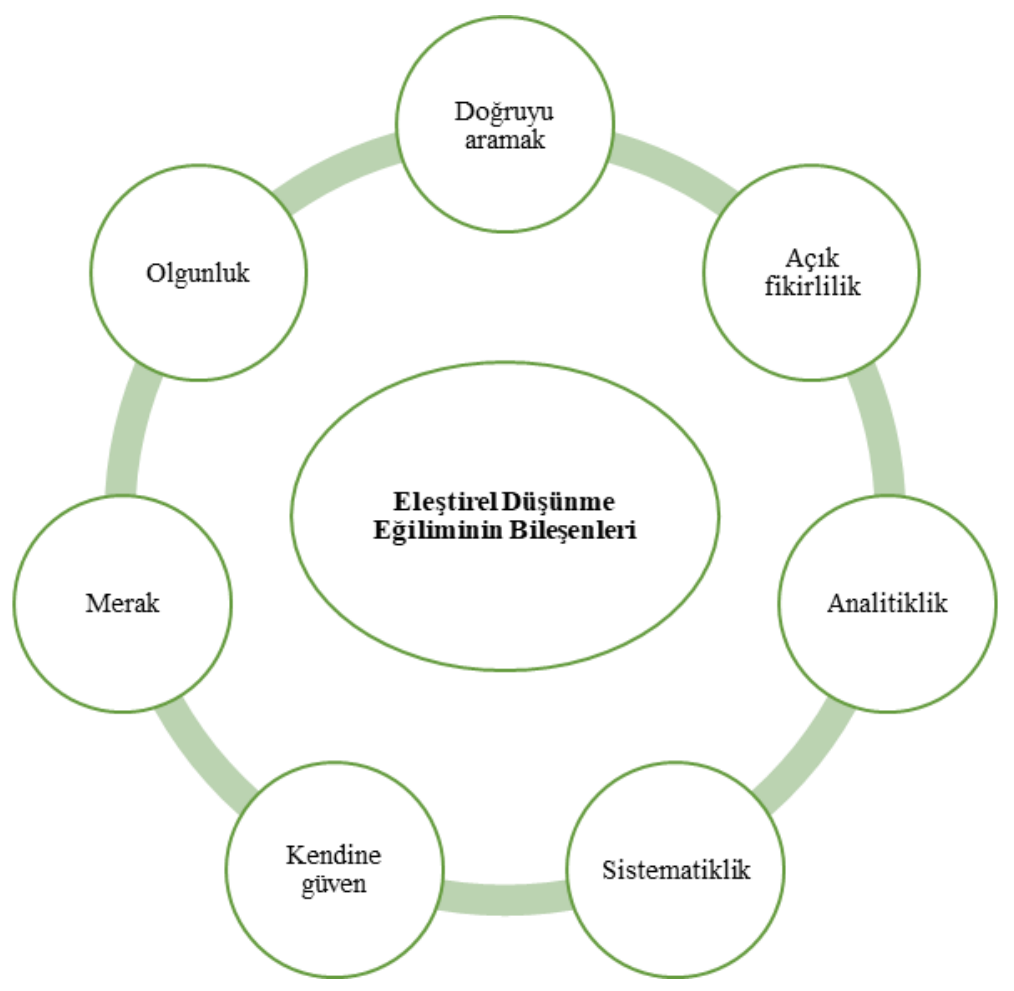

Şekil 1. Eleştirel düşünmenin bileşenleri (Faccione P., Faccione N. ve Giancarlo, 2000'den uyarlanmıştır.)

Bireylerin eleştirel düşünme eğilimini birçok yönden etkileyen faktörler vardır. $\mathrm{Bu}$ faktörler hem eleştirel düşünme becerisinin hem de eleştirel düşünme eğiliminin oluşmasında ve gelişmesinde rol oynamaktadır. Eleştirel düşünme eğilimini etkileyen faktörlerden biri cinsiyettir. Cinsiyet faktörü; her toplumda kendisine farklı roller biçilmesi, biyolojik ve psikolojik farkl1lıklar meydana getirmesi sebebiyle önemlidir. Cinsiyet rolleri, toplum tarafından belirlenen ve sınırları toplum tarafından çizilen rollerdir. Toplum içerisinde bir beceri, bir cinsiyet grubuna uygun görülmemişse o cinsiyet grubu o beceriyi kazanma veya onu kullanmaya eğilimli olmada olumlu ya da olumsuz etkilenebilir. Örneğin bazı toplumlarda, özellikle kadınlara söz hakkı erkeklere göre daha az tanınır ve kadınların eleştirmesinin, eleştirilerini dile getirmesinin önüne geçilir. Böyle toplumlarda kadın cinsiyet gruplarının eleştirel düşünme eğilimi noktasında cinsiyet rolünden olumsuz etkilenmesi doğal bir durumdur. Cinsiyet faktörünün biyolojik ve psikolojik boyutlarda da farkl11ıklara sebep olduğu gerçekleştirilen araştırmalarla ortaya konmuştur. Eşel (2005) kadın ve erkek beynini; duyguları anlama, algılama, konuşma yeteneği, uzaysal ve matematiksel yetenekler, hafıza ve tutum yönünden incelemiş ve duyguları anlama, algılama 
hızı, konuşma yeteneği, sözel hafıza alanlarında kadınların erkeklere oranla daha başarılı olduğunu; uzaysal yeteneklerde erkeklerin daha başarılı olduğunu, matematiksel yeteneklerde belirsiz bir durum olduğunu, kadın ve erkeğin hayata karşı tutumlarında bazı alanlarda birbirinden tamamen farklı olduğunu tespit etmiştir. Bunun dışında bireylerin yaşının; eleştirel düşünme eğilimini bedensel, zihinsel, bilişsel, duyuşsal, psikolojik vb. alanlardaki gelişimi açısından etkilediği söylenebilir. Örneğin Piaget (2019, s.36), algısal etkinliklerin nicelik ve nitelik açısından yaş düzeyine bağlı olduğu ve yaşla birlikte geliştiğini ifade etmiştir. Ay ve Akgöl (2008) gerçekleştirdiği araştırmada yaş düzeyinin eleştirel düşünme gücünü etkilediğini ifade etmiştir. Yaş düzeyinin pek çok olgunluğu beraberinde getirmesi nedeniyle eleştirel düşünmede rol oynadığı söylenebilir. Alan yazında incelenen bir diğer faktör de bireyin sahip olduğu anne ve babanın eleştirel düşünme becerilerine yönelik davranış, inanç ve tutumlarıdır. Tümkaya ve Aybek'in (2008) çalışmasında bireyin en çok vaktini geçirdiği ve dil öğrenirken bile en çok örnek aldığ annenin eğitim durumunun, bireyin eleştirel düşünme eğilimini anlamlı bir şekilde farklılaştırdığı görülmüştür. Bu nedenle anne ve babanın evde oluşturduğu tutumun otoriter, korumacı veya demokratik oluşu, bireyin ev ortamında ne kadar söz hakkı olduğunu ve düşüncelerinin ne kadar dikkate alındığını belirleyebilir. Bunun yanında öğretmen ve okul faktörünün, bireyin eleştirel düşünme eğilimini şekillendirmede rol oynadığı söylenebilir. Okul ve öğretmen faktörü, eğitim ve öğretim amaciyla yetiştirdikleri öğrencilerin gelişiminden ve gerekli kazanımları elde etmesinden sorumludur. Bu nedenle eğitim anlayışları ve öğrenciyi eleştirel düşünme yönünde destekleyecek bir okul ve sınıf ortamı oluşturmaları, eğilimin oluşmasında rol oynayabilir. Eleştiren ve sorgulayan bireyler yetiştirilebilmesi için önce öğretmenlerin bu nitelikleri taşıması ve öğrenciye bunları nasıl öğretmesi gerektiğini bilmesi gerektiği ifade edilmiştir (Aybek, 2007). Bunların dişında bireyin algılanan kişilik özellikleri, sosyo-ekonomik düzeyi, akademik başarısı, içerisinde yaşadığı toplum ve kültür de eleştirel düşünme eğilimini etkileyen faktörler arasında sayılabilir.

Eleştirel düşünme eğilimini etkileyen bu faktörler, bireyin eğitim sürecinde önemli bir kavram hâline getirmiştir. $\mathrm{Bu}$ eğilimin özellikle eğitim sürecindeki bireylere kazandırılması sonucunda bu bireylerin yaşamları boyunca ifade edilenlere yönelik becerilerde eleştirel düşünme eğilimi sayesinde başarılı olabileceği söylenebilir. Eleştirel düşünme eğiliminin dil ve düşünme becerilerini geliştirmesi doğrultusunda özellikle bu becerilerin kademeli olarak öğretildiği ortaokul düzeyindeki öğrencilerde mevcut olması 
S, Yıldırım Döner ve S, Demir/ Pamukkale Üniversitesi Eğitim Fakültesi Dergisi, 54, 99-129, 2022

önem arz etmektedir. Çünkü ortaokul düzeyinde dil ve düşünme becerileri sezdirme yönteminin ötesinde açıklanmakta ve öğrencilere bir bilinç kazandırılarak öğretilmektedir. Yani öğrencinin ortaokul düzeyinde eleştirel düşünme eğilimini ne kadar kavradığı, bu eğilime sahip olup olmadığı gibi durumlar, onun dil ve düşünme becerilerini kazanmasında da etkili olacaktır. Alan yazın incelendiğinde geliştirilen eleştirel düşünme eğilim ölçeklerinin örneklem gruplarının farklılaştığı ancak direkt olarak ortaokul öğrencilerine yönelik olmadığı görülmüştür. Bu doğrultuda ortaokul öğrencilerine yönelik bir eleştirel düşünme eğilimi ölçeğinin alan yazında yer almasının, öğrencilerin eleştirel düşünme eğilim düzeylerini ölçmek için faydalı olacağı düşünülmüştür. Semerci (2016) tarafindan geliştirilen Eleştirel Düşünme Eğilimi (EDE) Ölçeği, öğretmen adayları ve öğretmenlere; Ertaş Kılıç ve Şen (2014) tarafından Türkçeye uyarlanan UF/EMI Eleştirel Düşünme Eğilimi Ölçeği lise düzeyindeki öğrencilere; Demircioğlu (2012) tarafından Türkçeye uyarlanan Ricketts ve Rudd tarafından 2005 yılında geliştirilen Eleştirel Düşünme Eğilimi Ölçeği lise düzeyindeki öğrencilere; Akın ve arkadaşları (2015) tarafından geliştirilen Eleştirel Düşünme Eğilimi Ölçeği üniversite düzeyindeki öğrencilere; Kökdemir (2003) tarafından Türkçeye uyarlanan California Eleştirel Düşünme Eğilimi Ölçeği üniversite düzeyindeki öğrencilere uygulanmıştır. Görüldüğg̈ gibi alan yazında ortaokul düzeyindeki öğrenciler için bir ölçek eksikliği bulunmaktadır. Bu nedenle ortaokul öğrencilerine yönelik (9-14 yaş arası) bir eleştirel düşünme eğilimi ölçeğinin alan yazına katkı sağlayacağ1 düşünülmektedir. $\mathrm{Bu}$ doğrultuda araştırmanın amacı, ortaokul öğrencilerinin eleştirel düşünme eğilim düzeylerini belirleyecek geçerli ve güvenilir bir Eleştirel Düşünme Eğilimi Ölçeği geliştirmektir.

\section{Yöntem}

Araştırma; nicel araştırma türünde, tarama modelinde gerçekleştirilmiştir. Ölçme, bireylerin ya da nesnelerin sahip olduğu niteliklerin bir araç yoluyla sınıflandırılması, sıralanması, aralıklandırılması veya oransal olarak açıklanmasıdır (Büyüköztürk, Kılıç Çakmak, Akgün, Karadeniz ve Demirel, 2018, s.106-107). Ölçme kavramı, nicel araştırmalarda ölçme araçlarından elde edilen verilerin genellenebilir olması nedeniyle güvenirlik ve geçerlik kavramlarıyla birlikte önem arz eder (Sönmez ve Alacapınar, 2017, s. 187). Ölçek geliştirme sürecinde, anılanların ışığında, öncelikle problem tanımlanır, alan yazından hareketle ölçek için maddeler yazılır, ardından uzman görüşü alınarak ön uygulama gerçekleştirilir, son olarak gerekli analizler yapılır ve ölçeğe son şekli verilir (Büyüköztürk ve diğerleri, 2018, s. 
130-140). Likert tipi ölçekler teorik olarak cevaplar arasında eşit aralıkların var olduğu kabul edilir (Creswell, 2017).

\section{Evren ve Örneklem}

Araştırmanın evrenini 2019-2020 eğitim ve öğretim yılında devlet okullarında öğrenim gören ortaokul öğrencileri oluşturmaktadır. Hedef evrene ulaşmak mümkün görülmediğinden ulaşılabilir evren olarak Tokat il merkezinde bulunan devlet ortaokul öğrencileri belirlenmiştir. Ölçme aracı geliştirilirken her analizde belirlenen evren içerisinden farklı örneklem grupları kullanılmıştır.

Öncelikle Tokat il merkezindeki devlet okullarının isimleri kâğıtlara yazılmış ve bir torba içerisine konulmuştur. Ölçeğin ilk aşaması için seçilen okullar bu torbadan rastgele seçilmiştir. Uygulamanın gerçekleşeceği birinci okul bu şekilde seçildikten sonra belirlenen okulun kâğıdı tekrar torbaya konulmuş ve ikinci okul da aynı yöntemle seçilmiştir. Belirlenen ortaokulların sınıf ve şube bilgileri alınarak her okulun sınıf düzeyleri ve şubeleri 5, 6, 7 ve 8. sınıf olmak üzere kâğıtlara yazılarak ayrı ayrı torbaya konmuştur. Her sınıf düzeyi için ayrı ayrı gerçekleşen seçilimde her bir okulun 9-14 yaş grubu içerisinde yer alan her bir sınıf düzeyinde 2 farklı şube belirlenmiştir. Böylece ölçeğin ilk uygulaması olan açımlayıcı faktör analizi (AFA); toplamda 2 okul, 4 sınıf düzeyi (5-8), 16 sınıf şubesinde olmak üzere 503 öğrenci üzerinden gerçekleştirilmiştir.

Ardından ölçeğin test-tekrar test uygulaması için Tokat il merkezindeki devlet okulları tekrar kâğıtlara yazılarak bir torba içerisine konulmuş ve rastgele seçilim yöntemiyle farklı bir ortaokul seçilmiştir. Belirlenen okulda 5, 6, 7 ve 8. sınıf düzeylerinden küme örnekleme yöntemiyle birer şube seçilmiş ve bu şubelerde 15 gün aralıkla 2 ayrı uygulama gerçekleştirilmiştir. İlk uygulamada 122, ikinci uygulamada 112 öğrenciye ulaşılmıştır. Daha sonra sadece ilk veya ikinci uygulamaya katılanlar ile formu özensiz dolduran öğrencilerin formlarının geçersiz sayılmasıyla analiz, 90 öğrenci üzerinden gerçekleştirilmiştir.

Son olarak ölçeğin model uyumunu sağlayacak olan doğrulayıcı faktör analizi (DFA) için tekrar basit seçkisiz örnekleme yöntemi uygulanmış ve Tokat il merkezindeki bir ortaokul, kâğıtlar arasından torbada rastgele bir seçilimle belirlenmiştir. Bu okulda 5, 6, 7 ve 8 olmak üzere her sınıf düzeyinden küme örnekleme yöntemiyle 4'er şube seçilmiş ve ölçeğin bu uygulaması toplamda 506 öğrenci üzerinden gerçekleştirilmiştir. Okullar ve şubeler belirlenirken her seferinde basit seçkisiz örnekleme ve küme örnekleme yöntemi 
S, Yıldırım Döner ve S, Demir/ Pamukkale Üniversitesi Eğitim Fakültesi Dergisi, 54, 99-129, 2022

kullanılmıştır. Araştırmanın her analizinde, farklı bir örneklem grubundan veri toplanmasına dikkat edilmiştir. Bu doğrultuda araştırma uygulamaları birbirinden farklı olmak üzere; AFA için 2, test-tekrar test analizi için 1, DFA için 1 ortaokulda gerçekleştirilmişstir.

\section{İşlem}

Ortaokul öğrencilerinin eleştirel düşünme eğilimlerinin düzeyini ölçmek amacıyla araştırmacılar tarafından Eleştirel Düşünme Eğilimi Ölçeği geliştirilmiştir. Ölçek geliştirme çalışması için öncelikle alan yazında geniş bir tarama yapılmış ve ortaokul öğrencilerine uygun olabilecek şekilde eleştirel düşünme eğilimine yönelik 43 maddelik bir madde havuzu oluşturulmuştur. Oluşturulan bu maddelerin kapsam geçerliliğini sağlamak için Lawshe Tekniği (1975) kullanılmış, bu kapsamda ölçek taslağı uzman görüşlerine sunularak Lawshe kapsam geçerlik indeksi (KGI) (content validity ratio - CVR) hesaplanmıştır. 6 Türkçe eğitimi, 2 eğitim bilimleri alanından olmak üzere toplamda 8 akademisyenden görüş alınmış ve bu görüşlerin değerlendirilmesinde Lawshe Tekniği kapsamında KGİ anlamlılık değerinin 8 uzman görüşünde en az .78 düzeyinde olması gerektiği göz önünde bulundurulmuştur (Yurdugül, 2005). Uzmanlardan her bir madde için "gerekli, düzeltilmeli, çıkarılmalı" şeklinde görüş bildirmeleri istenmiş ve elde edilen görüşler doğrultusunda ölçek taslağındaki maddelerin kapsam geçerlilik indeksi .78 olarak hesaplanmıştır. Belirlenen değerin istatistiksel anlamlılı̆̆ ve kapsam geçerlilik indeksini sağlaması nedeniyle ölçekten hiçbir madde çıkarılmamıştır. Bunun dışında maddelerde “düzeltilmeli” seçeneğini seçen ve düzeltme noktasında öneride bulunan uzmanların görüşü dikkate alınmıştır ve ölçek buna göre şekillendirilmiştir.

Resmî izinler alındıktan sonra taslak ölçeğin ilk uygulaması, Tokat il merkezinde basit seçkisiz örnekleme ile belirlenen 2 ortaokulda "madde sayısı $\times 10(43 \times 10=430)$ " formülü doğrultusunda 5-8. sınıf düzeylerinde küme örnekleme yöntemi ile belirlenen ikişer şubede olmak üzere toplamda 504 öğrenci ile gerçekleştirilmiştir. SPSS programına aktarılan verilere yapı geçerliliğine dair kanıt elde etmek ve faktör yapısını doğrulamak amacıyla açımlayıcı faktör analizi yapılmıştır (Çokluk, Şekercioğlu ve Büyüköztürk, 2018). Yapı geçerliği ölçmek için ilk olarak verilere faktör analizin yapılıp yapılamayacağını belirlemek ve örneklem büyüklüğünün faktörleşmeye uygunluğunu test etmek için KaiserMeyer-Olkin (KMO) testi ile Barlett küresellik testi uygulanmıştır. İç tutarlılı̆̆ ölçmek için taslak ölçek uygulamasında elde edilen veriler üzerinden ölçek geneline Cronbach's Alpha güvenirlik analizi gerçekleştirilmiştir. Ardından ölçeğin her alt boyutu için Cronbach's Alpha testi yapılmış ve her faktörün kendi maddeleri içindeki ilişki düzeyi kontrol 
edilmiştir. Ölçek maddelerinin toplam varyansa ve ölçek ortalamasına etkisi, madde öz değerleri, düzeltilmiş madde-toplam korelasyonu ve ölçeğin güvenirlik değerleri incelenmiştir.

Ortaokul Öğrencileri İçin Eleştirel Düşünme Eğilimi Ölçeği’nin daha güvenilir olması ve hesaplanan güvenirliklerin sağlanarak yapısal geçerliliğinin ortaya konulması amaciyla Tokat il merkezinde basit seçkisiz örnekleme yöntemiyle belirlenen başka bir okulda 5, 6, 7 ve 8.sınıf düzeylerinde birer şubeye test-tekrar test uygulaması yapılmıştır. Elde edilen veriler SPSS programı aracılığıyla bilgisayar ortamına aktarılmış ve gerçekleştirilen test-tekrar test uygulamasının analizi sonucunda ölçeğin iç tutarlılık katsayısı iyi düzeyde güvenilir kapsamında " $r=.75$ " olarak tespit edilmiştir. Bu doğrultuda Eleştirel Düşünme Eğilimi Ölçeği’nin yeterli düzeyde iç tutarlılığa sahip olduğuna karar verilmiştir.

Ortaokul Öğrencileri İçin Eleştirel Düşünme Eğilimi Ölçeği'nin bir model olarak doğrulanıp doğrulanmadığını ve faktör analizi üzerine kurulu hipotezlerin test edilmesi amacıyla doğrulayıcı faktör analizi yapılmasına karar verilmiştir (Çokluk ve diğerleri, 2018, s. 275). Tokat il merkezinde basit seçkisiz örnekleme yöntemi ile seçilen farklı bir ortaokulda 5-8. sınıf düzeylerinin her birinde küme örnekleme ile belirlenen 4'er şubede öğrenim gören 506 öğrenci üzerinden DFA yapılmıştır. Elde edilen veriler bilgisayar ortamına aktarılmış ve DFA uygulaması LISREL programı üzerinden gerçekleştirilmiştir. Ölçeğin model uyumunda ki-kare $\left(\mathrm{X}^{2}\right)$ değeri, ki-kare değerinin sd'ye oranı, RMSEA, Standardized RMR, NFI, NNFI, CFI, GFI ve AGFI değerleri kullanılarak ölçeğin model uyum ölçüleri ortaya konmuştur (Çokluk, Şekercioğlu, Büyüköztürk, 2012). DFA sonucunda modelin CFI, NFI, NNFI (TLI), RFI, IFI, RMSEA değerlerinde mükemmel uyumu; AGFI, GFI, SRMR, PNFI ve PGFI değerlerinde kabul edilebilir/iyi uyumu sağladığ görülmüştür (Sümer, 2000, s. 68; Brown 2016'dan akt. Çokluk, Şekercioğlu, Büyüköztürk, 2012, s. 272).

\section{Bulgular}

$\mathrm{Bu}$ bölümde araştırma sonucunda elde edilen bulgular tablolaştırılmış ve alan yazından hareketle açıklanmıştır.

\section{Açımlayıcı Faktör Analizi}

Ölçeğin yapısının belirlenmesi ve yapı geçerliliğini ortaya koymak amacıyla, ön uygulamanın ardından elde edilen veriler üzerinde açımlayıcı faktör analizi (AFA) 
S, Yıldırım Döner ve S, Demir/ Pamukkale Üniversitesi Eğitim Fakültesi Dergisi, 54, 99-129, 2022

gerçekleştirilmiştir. AFA ile ölçeğin faktör yapısı ve maddeleri belirlenmiş, yapı geçerliliğini sağlayıp sağlamadığı tespit edilmiştir.

Tablo 1. Ortaokul Öğrencileri Iç̧in Eleştirel Düşünme Eğilimi Ölçeği'nin KMO ve Barlett's Testi

\begin{tabular}{lcc}
\hline Kaiser-Meyer-Olkin Örnekleme Yeterliğinin Ölçümü & .938 \\
Barlett Küresellik Testi & Yaklaşık Ki-Kare & 6125.515 \\
& df & 903 \\
& sig & .000 \\
\hline
\end{tabular}

Verilere AFA'nın yapılıp yapılamayacağını belirlemek ve örneklem büyüklügüünün faktörleştirmeye uygunluğunu test etmek için gerçekleştirilen testlerde ölçeğin KMO değerinin .94 olduğu belirlenmiştir. Bu değerin .90 üzerinde olduğu için "mükemmel" düzeyde olduğu söylenebilir (Jackson ve Holland, 2003’ten akt. Şencan, 2005, s. 384). Ardından Barlett Küresellik Testi sonuçlarında sig değerinin .000 olduğu ve elde edilen kikare değerinin anlamlı olduğu $(\chi 2(903)=6125.515 ; p<.01)$ görüldüğünden faktör analizi gerçekleştirilmiştir.

Ölçeğin faktör desenini ortaya koymak amacıyla faktörleştirme yöntemi olarak temel bileşenler analizi, döndürme yöntemi olarak da dik döndürme yöntemlerinden maksimum değişkenlik (varimax) belirlenmiştir.

Analiz sonucunda analize temel olarak alınan 43 madde arasındaki ilişkinin $r>.30$ olduğu ve matris determinant değerinin .0001 'den büyük olduğu görülmüştür. Maddeler arasında çoklu eşdoğrusallık $(r>.80)$ tespit edilmediğinden ve anti-imaj korelasyon matrisindeki maddelerin kesişim değerleri de .50'nin üstünde olduğundan ölçekten madde çıkartılmamıştır. Ortaya çıkan bileşenler matrisinde (component matrix), ölçme aracındaki 43 maddenin birinci faktör yük değerinin .458 ve üzerinde olduğu tespit edilmiştir. Analize temel olarak alınan 43 madde için öz değerleri 1'in üzerinde olan 9 faktör tespit edilmiştir. $\mathrm{Bu}$ faktörlerin varyansa yaptığı katkının \%49.396 olduğu görülmüştür. Faktör sayısına karar vermek için faktörlerin toplam varyans değerleri incelenmiş ve ilk iki bileşenin varyansa katk1 sağladığı, üçüncü bileşenden sonra varyansa sağlanan katkının giderek azaldığı tespit edilmiştir. Buna göre ölçek için 2 veya 3 faktör belirlenebileceği düşünülmüşse de yamaç birikinti grafiğinin (Scree Plot) incelenmesinde fayda görülmüştür. 


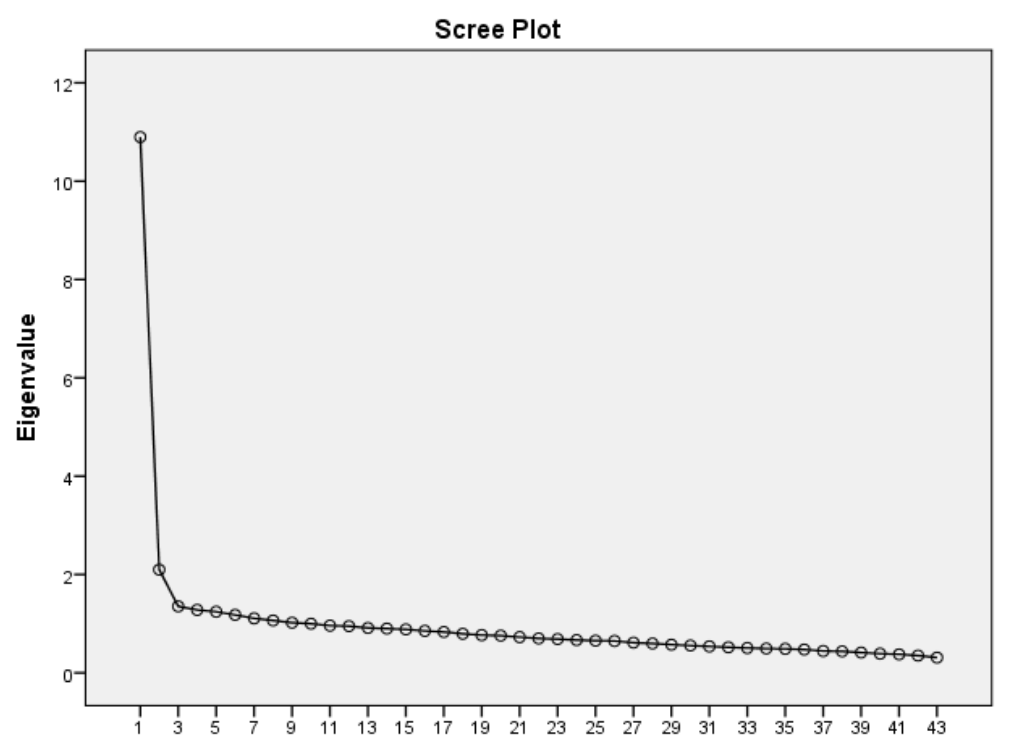

\section{Şekil 1. Faktör sayısına ilişkin yamaç-birikinti grafiği}

Şekilde, bileşenlerin $\mathrm{X}$ eksenine doğru inişte olduğu görülmektedir. İki nokta arasındaki kırılmaların her biri faktör anlamına geldiğinden üçüncü noktadan sonra bileşenlerin varyansa yaptığı katkının azaldığ1 ve aynılaştığı doğrulanmıştır. Araştırmacılar tarafından, yamaç-birikinti grafiği ile uygunluk gösterdiği için faktör sayısının 3 olması kararlaştırılmıştır. $\mathrm{Bu}$ aşamadan sonra çok faktörlü AFA için her faktör altında en az \%10'luk varyansı açıklayabilen maddeleri görebilmek için normal değer .33 olarak girilmiştir (Can, 2018).

Faktör sayısına karar verildikten sonra döndürme işlemi gerçekleştirilmiştir. Ortaya çıkan döndürülmüş bileşenler matrisinde .33'ün altında olan ilişki düzeyine sahip olan maddeler sırasıyla tek tek çıkarılmış ve her seferinde analiz tekrarlanmıştır. Bu süreçte m5, m6, m16, m23, m30, m34, m37, m42, m43 maddeleri yüksüz $(\mathrm{r}<.33)$ olduğu için ölçekten çıkarılmıştır. Birden fazla faktörle ilişkisi olan madde ise görülmediğinden hiçbir madde binişik madde olarak kabul edilmemiştir. Ardından ölçeğin faktör analizi, faktör yapılarını güçlendirmek amacıyla “.45” değeri girilerek tekrar gerçekleştirilmiştir. Bu işlem sonucunda “.45” değeri altındaki $(\mathrm{r}<.45) \mathrm{m} 1, \mathrm{~m} 2, \mathrm{~m} 8, \mathrm{~m} 9, \mathrm{~m} 10, \mathrm{~m} 11, \mathrm{~m} 14, \mathrm{~m} 18, \mathrm{~m} 19, \mathrm{~m} 24, \mathrm{~m} 31, \mathrm{~m} 36$ maddeleri de ölçekten çıkarılmıştır. 22. madde Rotated Component Matrix’te 56 yük değerine sahip olmasına rağmen literatür kaynaklı kavramsal tutarlılığın sağlanabilmesi için ölçekten çıkarılmıştır. 
Döndürme Sonras1

Maddeler

Ortak $\quad 2 . \quad 3$.

Varyans Faktör Faktör Faktör

Yükü Yükü Yükü

15. Fikirlerimin arkasında durabilirim.

29. Problem çözme konusunda kendime

güvenirim.

17. Bir probleme getirdiğim çözümün neden

doğru olduğunu açıklayabilirim.

7. Problemlere ürettiğim çözümleri paylaşırken

kendime güvenirim.

21. Kendi düşüncelerimin farkındayımdır.

3. Çevremdeki insanların fikirlerini dikkatlice

dinlerim.

35. Olayların detaylarına odaklanabilirim.

27. Bir olayın temelindeki nedenleri keşfetmek

benim için önemlidir.

13. Bir durumu tüm yönleri ile $.322 \quad .518$ tanımlayabilirim.

33. Düşünce sürecimde temel amacim $.421 \quad .508$ doğrulara ulaşmaktır.

20. Bilgiyi edinmeye meraklıyımdır.

4. İnsanların fikirlerini dayandırdıkları $.325 \quad .502$ nedenleri önemserim.

40. Eleştirel düşünme benim için önemlidir. .673

41. Eleştirel düşünmenin bana katkı sağladığını .603 
düşünüyorum.

38. Eleştirel düşünmeyi severim.

39. Günlük hayatta eleştirel düşünmeye

başvururum.

12. Karşıt fikirleri değerlendirirken tarafsız $\quad .473$

davranırım.

32. Mantık hatalarını tanımlayabilirim.

28. Çevremdeki insanların fikirlerini objektif

bir şekilde dinlerim.

26. Bir cümledeki ön yargıyı sezebilirim.

25. İnsanlarla herhangi bir konuda .284 tartışmalarda bulunmayı severim.

Açıklanan toplam varyans tablosunda ölçeğe ait tüm maddelerin, değerlerin kabul düzeyini (.45) karşıladığı tespit edilmiştir. Bunun sonucunda ortaokul öğrencileri için Eleştirel Düşünme Eğilimi Ölçeği’nde 21 madde kalmıştır. Ardından analizlerle belirlenen 3 faktör yapısı, alan yazına uygun olarak adlandırılmıştır. 1. faktörde yer alan maddelerin karşıt durumlardan hareketle akıl yürütmeye ve öğrencinin kendi sentezine ulaşmadaki eğilimini ölçmeye yönelik maddeler (örn. Düşünce sürecimde temel amacım doğrulara ulaşmaktır.) olmaları nedeniyle bu faktör diyalektik düşünme olarak adlandırılmıştır. 2. faktörde yer alan maddelerin direkt olarak bireydeki eleştirel düşünme eğilimini ölçmeye yönelik maddeler (örn. Eleştirel düşünmeyi severim.) olmaları nedeniyle bu faktör eğilim olarak adlandırılmıştır. 3. faktörde yer alan maddelerin bireydeki analiz ve değerlendirmeye yönelik eğilimi ölçmesi nedeniyle (örn. Bir cümledeki ön yargıyı sezebilirim.) bu faktör analiz olarak adlandırılmıştır. 1. faktör (Diyalektik Düşünme) altında 12 (m15, m29, m17, m7, m21, m3, m35, m27, m13, m33, m20, m4); 2. faktör (Eğilim) altında 4 (m40, m41, m38, m39); 3. faktör (Analiz) altında 5 (m12, m22, m38, m26, m25) madde kalmıştır.

Açıklanan toplam varyans tablosu incelendiğinde 1.faktör için toplam varyans $\% 18.9$, 2. faktör için toplam varyans $\% 12.4$, 3. faktör için toplam varyans $\% 11.60$ olarak tespit edilmiştir. Toplamda üç faktörün, varyansı açıklama oranının \%42.94 olduğu bulgusuna ulaşılmıştır. Çok boyutlu ölçeklerde toplam (cumulative) değerinin en az \%40 
S, Yıldırım Döner ve S, Demir/ Pamukkale Üniversitesi Eğitim Fakültesi Dergisi, 54, 99-129, 2022

olması gerektiği bilgisinden hareketle gerçekleştirilen faktör analizinin kabul edilebilir olduğu söylenebilir.

\section{Güvenirlik Analizleri}

Eleştirel Düşünme Eğilimi Ölçeği’nin geçerlik ve güvenirlik katsayısını belirlemek amacıyla Cronbach'a Alpha, Spearman-Brown ve Guttman Split-Half güvenirlik katsayıs1 hesaplanmıştır:

Tablo 3. Cronbach's Alpha, Spearman-Brown, Guttman Split-Half Güvenirlik Testi

\begin{tabular}{lcccc}
\hline \multicolumn{1}{c}{ Ölçek } & $\begin{array}{c}\text { Cronbach's } \\
\text { Alpha Katsayıs1 }\end{array}$ & $\begin{array}{c}\text { Spearman-Brown } \\
\text { Katsayısı }\end{array}$ & $\begin{array}{c}\text { Guttman Split-Half } \\
\text { Katsayıs1 }\end{array}$ \\
\hline $\begin{array}{l}\text { Eleştirel } \\
\text { Ölçeği }\end{array}$ & Düşünme Eğilimi & .868 & .805 & .805 \\
\hline
\end{tabular}

Ölçeğin güvenirlik katsayısı, -1 ve +1 arasında değer alır, ancak +1 'e ne kadar yakınsa o kadar güvenirlik değeri verir (Can, 2018). Ortaokul öğrencileri için Eleştirel Düşünme Eğilimi Ölçeği'ne uygulanan güvenirlik testi sonucunda Cronbach's Alpha değeri .87 olarak tespit edilmiştir. Bu değer, Cronbach's Alpha güvenirlik katsayısı değerleri kategorilerinde "oldukça güvenilir" olarak belirlenmiştir. .00 $\leq \alpha<.40=$ güvenilir değil, .40 $\leq \alpha<.60=$ düşük derecede güvenilir, . $60 \leq \alpha<.90=$ oldukça güvenilir, $.90 \leq \alpha<1.00=$ yüksek derece güvenilir olarak kabul edilir (George ve Mallery, 2003'ten akt. Gliem ve Gliem, 2003). Ölçeğin güvenilirliğini sağlamak amacıyla Cronbach's Alpha testinin yanı sıra ölçek geneline Spearman-Brown ve Guttman Split-Half güvenirlik testleri uygulanmıştır. Spearman-Brown ve Guttman Split-Half güvenirlik katsayıları “.81” olarak hesaplanmış ve bu değerlerin oldukça güvenilir olduğuna kanaat getirilmiştir.

Gerçekleştirilen Cronbach's Alpha testi sonucunda düzeltilmiş madde-toplam korelasyon katsayısına bakıldığında hiçbir maddenin .20'nin altında olmadığı görülmüş ve bu nedenle ölçekten madde çıkarılmamıştır. Ölçeğin tamamında düzeltilmiş madde-toplam korelasyon katsayılarının .30'un üzerinde olduğu ve bu nedenle madde güvenirliklerinin iyi düzeyde olduğu görülmektedir 
112 S, Yıldırım Döner ve S, Demir/ Pamukkale Üniversitesi Eğitim Fakültesi Dergisi, 54, 99-129, 2022

Tablo 4. Ölçek maddelerine ilişkin güvenirlik katsayıları

\begin{tabular}{|c|c|c|c|c|c|}
\hline & $\begin{array}{c}\text { Madde } \\
\text { Silindiğinde } \\
\text { Ölçek } \\
\text { Ortalaması }\end{array}$ & $\begin{array}{c}\text { Madde } \\
\text { Silindiğinde } \\
\text { Ölçek Varyansı }\end{array}$ & $\begin{array}{c}\text { Düzeltilmiş } \\
\text { Madde-Toplam } \\
\text { Korelasyonu }\end{array}$ & $\begin{array}{c}\text { Çoklu } \\
\text { Korelasyon } \\
\text { Kareleri }\end{array}$ & $\begin{array}{c}\text { Madde } \\
\text { Silindiğinde } \\
\text { Cronbach's } \\
\text { Alpha }\end{array}$ \\
\hline M3 & 77.1885 & 144.809 & .455 & .293 & .859 \\
\hline M4 & 77.5079 & 143.749 & .435 & .272 & .860 \\
\hline M7 & 77.2679 & 144.964 & .452 & .265 & .859 \\
\hline M12 & 77.7937 & 145.607 & .315 & .189 & .865 \\
\hline M13 & 77.8016 & 144.291 & .462 & .273 & .859 \\
\hline M15 & 77.0456 & 147.185 & .399 & .234 & .861 \\
\hline M17 & 77.4008 & 141.843 & .549 & .347 & .856 \\
\hline M20 & 77.1687 & 145.361 & .440 & .241 & .860 \\
\hline M21 & 77.0853 & 144.599 & .516 & .333 & .858 \\
\hline M25 & 77.7540 & 143.426 & .398 & .198 & .862 \\
\hline M26 & 77.6151 & 142.734 & .479 & .272 & .858 \\
\hline M27 & 77.5536 & 142.474 & .510 & .348 & .857 \\
\hline M28 & 77.4306 & 144.926 & .414 & .218 & .861 \\
\hline M29 & 77.3214 & 143.873 & .485 & .309 & .858 \\
\hline M32 & 77.7202 & 142.242 & .500 & .309 & .858 \\
\hline M33 & 77.3671 & 142.467 & .521 & .371 & .857 \\
\hline M35 & 77.3909 & 145.734 & .436 & .239 & .860 \\
\hline
\end{tabular}


Alpha değeri .64 olarak tespit edilmiştir. Bu değer, Cronbach's Alpha güvenirlik katsayıs1 değerleri kategorilerinde oldukça güvenilir olarak belirlenmiştir.

\section{Test-Tekrar Test Uygulamast}

Eleştirel Düşünme Eğilimi Ölçeği’nin daha güvenilir olması ve hesaplanan güvenirliklerin sağlamasının yapılması amacıyla Tokat il merkezinde rastgele örnekleme yöntemiyle belirlenen bir okulda 5, 6, 7 ve 8. sınıf düzeylerinde birer şubeye test-tekrar test uygulaması yapılmıştır.

Tablo 6. Test-Tekrar Test korelasyon analizi

\begin{tabular}{|c|c|c|c|c|c|}
\hline & & Test & $\begin{array}{c}\text { Tekrar } \\
\text { Test }\end{array}$ & Ortalama & $\begin{array}{c}\text { Standart } \\
\text { Sapma }\end{array}$ \\
\hline \multirow{3}{*}{ Test } & $\begin{array}{l}\text { Pearson } \\
\text { korelasyon }\end{array}$ & 1.000 & $.748 * *$ & \multirow{3}{*}{3.86} & \multirow{3}{*}{.55} \\
\hline & Sig (2-tailed) & & .000 & & \\
\hline & $\mathrm{N}$ & 90 & 90 & & \\
\hline \multirow{3}{*}{ Tekrar Test } & $\begin{array}{l}\text { Pearson } \\
\text { korelasyon }\end{array}$ & $.748 * *$ & 1.000 & \multirow{3}{*}{4.02} & \multirow{3}{*}{.56} \\
\hline & Sig (2-tailed) & .000 & & & \\
\hline & $\mathrm{N}$ & 90 & 90 & & \\
\hline
\end{tabular}

Yapılan test-tekrar test uygulamasının analizi sonucunda ölçeğin iç tutarlılık katsayıs1 iyi düzeyde güvenilir kapsamında .75 olarak tespit edilmiştir ve bu değerin .01 düzeyinde anlamlı olduğu belirlenmiştir. $\mathrm{Bu}$ doğrultuda Eleştirel Düşünme Eğilimi Ölçeği'nin çok güçlü düzeyde iç tutarlılığa sahip olduğuna karar verilmiştir. Alan yazında ortaokul öğrencilerine yönelik eleştirel düşünme eğilimi temelinde başka bir ölçek bulunmadığından ölçüt geçerliğine ilişkin bir uygulama yapılmamıştır ancak Fırat Üniversitesi ve Amasya Üniversitesinde görev yapan Türkçe Eğitimi bölümündeki öğretim üyelerinden uzman görüşü alınmıştır. $\mathrm{Bu}$ nedenle test-tekrar test uygulamasına başvurulmuştur. Ayrıca farklı bir örneklem üzerinden gerçekleştirilen ikinci düzey çok 
S, Yıldırım Döner ve S, Demir/ Pamukkale Üniversitesi Eğitim Fakültesi Dergisi, 54, 99-129, 2022

faktörlü doğrulayıcı faktör analizi uygulamasında ölçüm modeli uyum indeksleri iyi ve mükemmel uyum düzeyleri gerçekleşmiştir.

\section{Doğrulayıcı Faktör Analizi}

Eleştirel Düşünme Eğilimi Ölçeği’nin bir model olarak doğrulanıp doğrulanmadığını ve faktör analizi üzerine kurulu hipotezlerin test edilmesi amaciyla ölçek, farklı bir örneklem üzerinden doğrulayıcı faktör analizine tabi tutulmuştur (Çokluk ve diğerleri, 2018). Üç faktörlü ölçeğin DFA'sı, AFA ile elde kalan 21 madde üzerinden gerçekleştirilmiştir. Eleştirel Düşünme Eğilimi Ölçeği'nin model uyumunu sınamak amacıyla LISREL 8.80 programı kullanılarak 21 madde üzerinden “ikinci düzey DFA” gerçekleştirilmiştir. DFA sırasında "ağırlıklandırılmış en düşük kareler kestirim metodu” kullanılmıştır.

Tablo 7. Eleştirel Düşünme Eğilimi Ölçeği'ne yönelik ikinci düzey doğrulayıcı faktör analizi sonucunda elde edilen ölçüm modeli

\begin{tabular}{|c|c|c|c|c|c|}
\hline Faktör & Maddeler & $\begin{array}{c}\text { Hata } \\
\text { Varyans1 }\end{array}$ & $\begin{array}{c}\text { Standartlaştırılmış } \\
\text { Yükler }\end{array}$ & $\mathrm{t}$-değeri ${ }^{1}$ & $\mathrm{R}^{2}$ \\
\hline & M6 & .60 & .63 & & .40 \\
\hline & M1 & .69 & .55 & 10.63 & .31 \\
\hline & M2 & .67 & .57 & 10.29 & .33 \\
\hline & M3 & .64 & .60 & 9.97 & .36 \\
\hline Diyalektik & M5 & .69 & .56 & 10.97 & .31 \\
\hline \multirow[t]{5}{*}{ Düşünme } & M7 & .47 & .72 & 7.51 & .53 \\
\hline & M8 & .69 & .56 & 10.49 & .31 \\
\hline & M9 & .67 & .57 & 10.24 & .33 \\
\hline & M12 & .64 & .60 & 10.06 & .36 \\
\hline & M14 & .53 & .69 & 8.01 & .47 \\
\hline
\end{tabular}

\footnotetext{
${ }^{1}$ İkinci düzey doğrulayıcı faktör analizi sırasında referans değişkenleri olarak belirlenen $\mathrm{m} 6, \mathrm{~m} 20$ ve $\mathrm{m} 4$ maddelerinin $t$ değerleri paylaşılmamıştır.
} 


\begin{tabular}{|c|c|c|c|c|c|}
\hline & M16 & .65 & .69 & 9.63 & .35 \\
\hline & M17 & .54 & .60 & 8.43 & .46 \\
\hline \multirow{4}{*}{ Eğilim } & M20 & .26 & .86 & & .74 \\
\hline & M18 & .47 & .73 & 7.22 & .53 \\
\hline & M19 & .33 & .82 & 5.49 & .67 \\
\hline & M21 & .38 & .79 & 6.05 & .62 \\
\hline \multirow{5}{*}{ Analiz } & M4 & .86 & .38 & & .14 \\
\hline & M10 & .89 & .68 & 16.19 & .11 \\
\hline & M11 & .78 & .47 & 12.48 & .22 \\
\hline & M13 & .82 & .43 & 13.29 & .18 \\
\hline & M15 & .59 & .82 & 8.48 & .41 \\
\hline
\end{tabular}

İkinci düzey doğrulayıcı faktör analizi sırasında referans değişkenleri olarak belirlenen m6, m20 ve m4 maddelerinin t değerleri paylaşılmamıştır.

DFA ölçüm modelinde öncelikle t değerleri kontrol edilmiş ve 2.56 sınırını aştığı için ölçeğin bütün maddelerinin $\mathrm{t}$ değerleri “.01” düzeyinde anlamlı olduğu için ölçekten herhangi bir madde çıkarılmamıştır. Maddelerin hata varyanslarının .33 ile .89 arasında olduğu ve tüm standartlaştırılmış hata yüklerinin “.30”dan büyük ".90”dan küçük olduğu belirlenmiştir. Bundan dolayı hata yüklerinin “.50” düzeyinde anlamlı olduğu görülerek hiçbir madde ölçekten çıkarılmamıştır. Diyalektik düşünme faktörüne ilişkin değişkenliğin en çok M7, en az M1 gözlenen değişkeni; eğilim faktörüne ilişkin değişkenliğin en çok M20, en az M18 gözlenen değişkeni; analiz faktörüne ilişkin değişkenliğin en çok M15, en az ise M3 gözlenen değişkeni tarafından açıklandığı görülmüştür. 
S, Yıldırım Döner ve S, Demir/ Pamukkale Üniversitesi Eğitim Fakültesi Dergisi, 54, 99-129, 2022

Tablo 8. İkinci düzey DFA sonucu ölçeğe yönelik düzeltme indeksleri

\begin{tabular}{|c|c|c|c|c|}
\hline & $\begin{array}{l}\text { İlişkilenen } \\
\text { Değişkenler }\end{array}$ & $\begin{array}{l}\text { İlişskilendirilen } \\
\text { Değişkenler }\end{array}$ & $\begin{array}{c}\text { Ki-Kare } \\
\text { Değerindeki } \\
\text { Azalma }\end{array}$ & $\begin{array}{c}\text { Yeni } \\
\text { Tahmin }\end{array}$ \\
\hline \multirow{5}{*}{$\begin{array}{l}\text { Birinci Kisım } \\
\text { Düzeltme İndeksleri }\end{array}$} & M6 & Eğilim & 8.6 & -.15 \\
\hline & M10 & Eğilim & 13.0 & .28 \\
\hline & M12 & Eğilim & 12.7 & .19 \\
\hline & M15 & Eğilim & 14.9 & -.30 \\
\hline & M16 & Eğilim & 8.5 & .16 \\
\hline \multirow{13}{*}{$\begin{array}{l}\text { İkinci Kısım Düzeltme } \\
\text { İndeksleri }\end{array}$} & M2 & M1 & 21.7 & .15 \\
\hline & M4 & M1 & 18.4 & .13 \\
\hline & M6 & M3 & 19.5 & .14 \\
\hline & M6 & M5 & 11.7 & -.11 \\
\hline & M9 & M2 & 11.8 & -.11 \\
\hline & M10 & M4 & 8.8 & .10 \\
\hline & M11 & M6 & 26.0 & .17 \\
\hline & M11 & M10 & 15.0 & .15 \\
\hline & M12 & M3 & 13.3 & -.11 \\
\hline & M12 & M4 & 15.2 & .11 \\
\hline & M13 & M5 & 11.2 & -.10 \\
\hline & M13 & M6 & 11.2 & .09 \\
\hline & M13 & M11 & 12.3 & -.11 \\
\hline
\end{tabular}




\begin{tabular}{|c|c|c|c|}
\hline M14 & M3 & 20.5 & .14 \\
\hline M14 & M4 & 9.7 & -.08 \\
\hline M14 & M10 & 12.8 & -.12 \\
\hline M14 & M11 & 8.4 & -.09 \\
\hline M15 & M5 & 8.4 & .09 \\
\hline M15 & M11 & 8.2 & .13 \\
\hline M15 & M14 & 9.0 & .09 \\
\hline M17 & M14 & 15.2 & .11 \\
\hline M17 & M16 & 13.4 & -.11 \\
\hline M18 & M7 & 10.4 & .08 \\
\hline M18 & M10 & 16.7 & .13 \\
\hline M18 & M13 & 9.4 & -.08 \\
\hline M19 & M7 & 13.2 & .08 \\
\hline M19 & M17 & 14.7 & .09 \\
\hline M20 & M7 & 10.2 & -.06 \\
\hline M20 & M12 & 16.0 & .09 \\
\hline M20 & M17 & 8.7 & -.06 \\
\hline M21 & M4 & 9.8 & -.08 \\
\hline M21 & M6 & 11.1 & -.08 \\
\hline M21 & M7 & 17.3 & -.09 \\
\hline M21 & M10 & 10.4 & -.09 \\
\hline
\end{tabular}


Birinci kısım düzeltme indeksleri, geliştirilen ölçeğin yapısına uygun bulunmadığından gerçekleştirilmemiştir. İkinci kısım düzeltme indekslerinden de farklı faktörler arasında uygulanması istenilenler, yine ölçeğin yapısını bozacağı endişesiyle araştırmacılar tarafından gerçekleştirilmemiştir. Bunların haricinde ikinci kısım düzeltme indeksleri kısmında yer alan ve $X^{2}$,ye katkı sağlayan m4 ile m13 ( $X^{2}$,ye 146.4'lük katkısıyla), m2 ile m3 ( $\mathrm{X}^{2}$,ye $39.8^{\prime}$ lik katkısıyla) hata varyansları arasındaki düzeltme önerisine yönelik kovaryans ataması gerçekleştirilmiştir. Gerekli modifikasyon gerçekleştirildikten sonra $\mathrm{X}^{2} /$ sd değerinin 1.875 ile 0 ve 2 arasında; RMSEA değerinin de .042 ile .00 ve .05 arasında; AGFI değerinin ise .85 ile .85 ve .90 arasında olması nedeniyle diğer modifikasyon önerilerine yönelik kovaryans ataması gerçekleştirilmemiştir. Bununla birlikte $\mathrm{p}$ değerinin .00000 ile .01 düzeyinde anlamlılığını sürdürdüğü görülmüştür. Oysaki DFA'da düzeltme işlemlerinden sonra beklenen kovaryans matrisi ile gözlenen kovaryans matrisleri arasındaki farkın yani $\mathrm{X}^{2}$ değerinin anlamlılı̆̆ını gösteren $\mathrm{p}$ değerinin (.00000) .01 düzeyinde anlamlı olmaması gerekmektedir. Ancak örneklemin büyüklüğü $(n=506)$ ile açıklanabilecek bu durum, gerek diğer uyum indekslerinin son derece iyi olması ve örneklem küçültmenin veri manipülasyonuna gireceği sebebi ile örneklem küçültme işlemine gidilmemiş, diğer uyum indeksleri de dikkate alınmıştır (Çokluk ve diğerleri, 2018).

Tablo 9. Eleştirel Düşünme Eğilimi Ölçeği model uyum ölçüleri

\begin{tabular}{ccc}
\hline Uyum Ölçüleri & Değer & Uyum \\
\hline $\mathrm{X}^{2}$ & 345.18 & $\mathrm{p}>.05$ \\
$\mathrm{X}^{2} / \mathrm{sd}$ & 1.875 & Mükemmel uyum \\
AGFI & .85 & İyi uyum \\
GFI & .88 & İyi uyum
\end{tabular}




$\begin{array}{ccc}\text { Uyum Ölçüleri } & \text { Değer } & \text { Uyum } \\ \text { CFI } & .99 & \text { Mükemmel uyum } \\ \text { NFI } & .97 & \text { Mükemmel uyum } \\ \text { NNFI (TLI) } & .98 & \text { Mükemmel uyum } \\ \text { RFI } & .96 & \text { Mükemmel uyum } \\ \text { IFI } & .99 & \text { Mükemmel uyum } \\ \text { RMSEA } & .042 & \text { Mükemmel uyum } \\ \text { SRMR } & .059 & \text { İyi uyum } \\ \text { PNFI } & .85 & \text { İyi uyum } \\ \text { PGFI } & .70 & \text { İyi uyum }\end{array}$

DFA sonucunda modelin uyum indeksleri incelendiğinde $X^{2}$ değerinin " 345.18 " ile .05 ’ten büyük olduğu ve bu yönüyle anlamlı olmadığı görülmüştür. Bu açıdan modelin iyi bir uyuma sahip olduğu söylenebilir. Örneklem büyüklüğünün önemli olduğu doğrulayıc1 faktör analizlerinde model uyumunun kontrol edilmesi için serbestlik derecesi (sd) ve kikare $\left(X^{2}\right)$ değerlerinin dikkate alınması gerekir (Çokluk, Şekercioğlu, Büyüköztürk, 2012, s. 267-268). Bu durumda ki-kare değerinin $\left(X^{2}\right)$ serbestlik derecesine bölünmesiyle $\left(\mathrm{X}^{2} / \mathrm{sd}=1.875\right)$ elde edilen değerin 0 ile 2 arasında olması model açısından mükemmel uyumu göstermektedir (Hoe, 2008 ve Şimşek, 2007'den akt. İlhan ve Çetin, 2014). Ayrıca modelin CFI, NFI, NNFI (TLI), RFI, IFI, RMSEA değerleri model açısından mükemmel uyumu; AGFI, GFI, SRMR, PNFI ve PGFI değerleri ise kabul edilebilir/iyi uyumu işaret ettiği söylenebilir (Sümer, 2000, s. 68; Brown 2016'dan akt. Çokluk, Şekercioğlu, Büyüköztürk, 2012). DFA analizi kapsamında gerçekleştirilen düzeltme işlemleri sonucunda 21 maddelik 3 faktörlü ortaokul 5, 6, 7 ve 8. sinıflar düzeyindeki öğrencilere yönelik Eleştirel Düşünme Eğilimi Ölçeği'nin model uyumunun kabul edilebilir olduğu, ölçek yapısının ise ikinci düzey DFA açısından doğrulandığı ifade edilebilir. 
S, Yıldırım Döner ve S, Demir/ Pamukkale Üniversitesi Eğitim Fakültesi Dergisi, 54, 99-129, 2022

Tablo 10. Ölçeğin dişsal gizil de ğişkenleri arasındaki korelasyon değerleri.

\begin{tabular}{lcccc}
\hline & $\begin{array}{c}\text { Diyalektik } \\
\text { Düşünme }\end{array}$ & Eğilim & Analiz & $\begin{array}{c}\text { Eleştirel } \\
\text { Düşünme Eğilimi }\end{array}$ \\
\hline Diyalektik Düşünme & 1.00 & & & \\
Eğilim & .40 & 1.00 & & \\
Analiz & .59 & .40 & 1.00 & \\
Eleştirel Düşünme Eğilimi & .75 & .84 & .78 & 1.00 \\
\hline
\end{tabular}

İkinci düzey DFA analizi sonucunda ölçeğin içsel gizil değişkenleri arasında orta düzeyde bir ilişki olduğu görülmüştür ( $r>30)$. Ayrıca dışsal gizil değişken ile içsel gizil değişkenler arasında çok güçlü düzeyde ( $r>.70)$ ilişki olduğu görülmüştür. Eleştirel Düşünme Eğilimi Ölçeği’nin yapı güvenirliğinin sınanabilmesi adına her bir gizil değişken ölçme modeli olarak düşünülmüş ve “yapı güvenilirliği=(standartlaştırılmış yükler toplamı)2/(standartlaştırılmış yükler toplamı)2+(gözlenen değişkenlerin ölçüm hataları toplamı)" formülü ile bu değişkenlerin yapı güvenirliği hesaplanmıştır (Çelik ve Yılmaz, 2016, s. 152). Gerçekleştirilen hesaplamalar sonucunda diyalektik düşünme alt boyutunun yap1 güvenirliği .88 , eğilim alt boyutunun .88 , analiz alt boyutunun .66; ölçeğin geneli için ise .93 olarak hesaplanmıştır. Bu bağlamda ilk iki alt boyutun ve ölçeğin genelinin yapı güvenirlik değerlerinin .70’ten büyük olması, ölçek için analiz alt boyutu dışında yapı güvenirliğinin sağlandığı ifade edilebilir. DFA sürecinde bakılması gereken diğer değer "açıklanan varyans= $($ standartlaştırılmış yüklerin kareleri toplamı) / (standartlaştırılmış yüklerin kareleri toplamı) + (gözlenen değişkenlerin ölçüm hataları toplamı)" formülü ile hesaplanacak olan açıklanan varyanstır (Çelik ve Yılmaz, 2016, s. 152). Eleştirel Düşünme Eğilimi Ölçeği’nin her bir gizil değişkenin açıklanan varyans ölçüm değerlerine ilişkin söz konusu formül kullanılarak yapılan hesaplamalar sonucunda diyalektik düşünme içsel gizil değişkeni .38, eğilim gizil değişkeni .64 ve analiz gizil değişkeni .30; ölçeğin geneli için ise .41 değerlerine ulaşılmıştır. Açıklanan varyans değerlerinin .50'den büyük olması beklenirken ölçeğin eğilim alt boyutu dışında diğer iki alt boyut ve ölçek genelinin bu değerin altında kaldığı tespit edilmiştir. Bunun yanında hem ölçeğin yapısal güvenirlik iyi olması ve özellikle de uyum indeksleri ve diğer parametrelerin oldukça iyi olması nedeniyle ölçeğin model uyumunun doğrulandığı söylenebilir. Eleştirel Düşünme Eğilimi Ölçeği’ne 

aşağıdaki şekildedir:

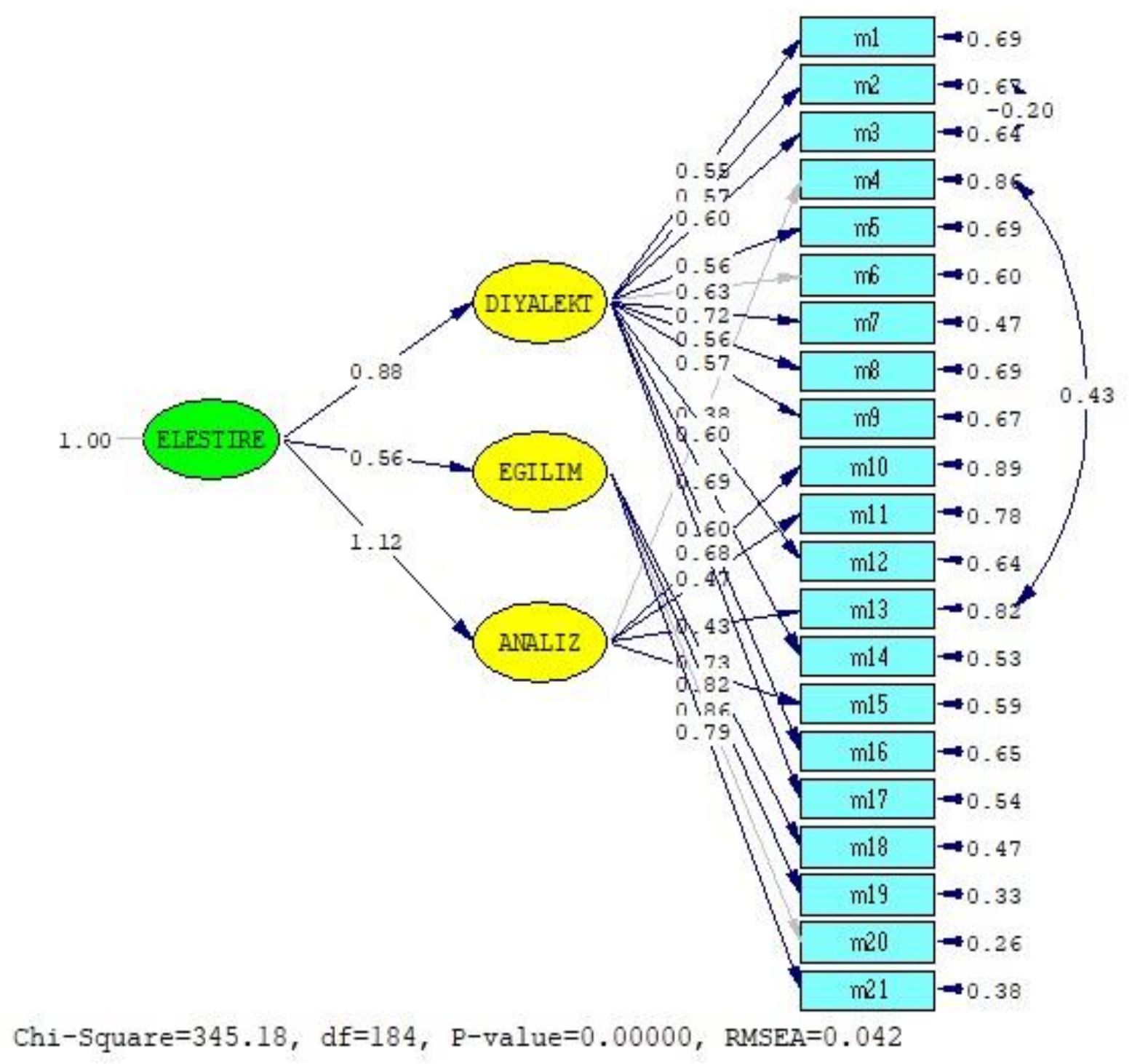

Şekil 3. Eleştirel Düşünme Eğilimi Ölçeği'ne yönelik modifikasyon işlemlerinden sonra elde edilen yol şemast.

LISREL programı kullanılarak gerçekleştirilen ikinci düzey DFA kapsamında öneriler doğrultusunda gerekli modifikasyon işlemleri yapılmış ve ölçeğe son şekli verilmiştir. Bu doğrultuda ölçeğin diyalektik alt boyutunda $\mathrm{m} 1, \mathrm{~m} 2, \mathrm{~m} 3, \mathrm{~m} 5, \mathrm{~m} 6, \mathrm{~m} 7, \mathrm{~m} 8$, m9, m12, m14, m16, m17 olmak üzere 12; eğilim alt boyutunda m18, m19, m20, m21 olmak üzere 4 ve analiz alt boyutunda $\mathrm{m} 4, \mathrm{~m} 10, \mathrm{~m} 11, \mathrm{~m} 13, \mathrm{~m} 15$ olmak üzere 5 ve toplamda 21 maddelik 3 boyutlu model uyumu sağlanmış bir ölçek olduğu söylenebilir. Aynı zamanda ikinci düzey DFA yapıldığından dolayı ölçeğin genel puanı üzerinden de analizlerde kullanılabileceği söylenebilir. 


\section{Tartışma ve Sonuç}

Araştırmada, ortaokul öğrencilerinin (9-14 yaş arası) eleştirel düşünme eğilim düzeylerini belirlemek için geçerli ve güvenilir bir ortaokul öğrencileri için Eleştirel Düşünme Eğilimi Ölçeği geliştirilmiştir. Eleştirel düşünme eğilimi, eleştirel düşünmenin gerçekleşmesi ve becerilerin kullanılması için gerekli bir unsurdur (Walker, 2003). Beceriler, eğilim olmadığ zaman kullanılamayacağı için körelebilir. Bu doğrultuda beceriyi tek başına öğretmenin yeterli olmayacağı, önemli olanın bireyde eğilim oluşturarak veya var olan eğilimi artırmak için destekleyerek beceriyi kullanmaya yönelik istek duyulmasını sağlamak olduğu ifade edilebilir (Halpern, 1998). Bu nedenle öğrencilerdeki eleştirel düşünme eğilim düzeylerinin belirlenmesi ve buna göre bir yol izlenmesi, öğrenciler ve sağlıklı bir eğitim süreci için önemlidir. Ortaokul seviyesinin eğitimde ilköğretimden ortaöğretime bir geçiş aşaması olduğu düşünülürse, bu dönemde öğrenciyi düşünme becerileri noktasında iyi bir seviyeye getirmenin ve durum tespiti yapmanın önem arz ettiği yorumunda bulunulabilir. $\mathrm{Bu}$ doğrultuda ölçek; alan yazında ortaokul öğrencilerinden oluşan bir örneklemle geliştirilmiş bir eleştirel düşünme eğilimi ölçeği tespit edilemediğinden, ortaokul seviyesindeki öğrencilere yönelik gerçekleştirilmiştir. Ölçek geliştirilirken ilgili alan yazın taranmış ve bundan hareketle 45 maddelik bir madde havuzu oluşturulmuştur. Oluşturulan madde havuzu Lawsche tekniği kapsamında 8 Türkçe eğitimi ve eğitim bilimleri alanına mensup akademisyen tarafından incelenmiş ve uzman madde değerlendirmeleri sonucunda maddelerin KGO değeri.78 olduğu için yeterli görülmüştür (Yurdugül, 2005). Ölçeğin gerekli düzeltmeleri yapıldıktan sonra AFA için ortaokul 5-8. sınıflar arasındaki 504 öğrenci üzerinden bir uygulama gerçekleştirilmiştir. $\mathrm{Bu}$ analizin sonucunda diyalektik düşünme, eğilim ve analiz adlı üç alt boyuta sahip Eleştirel Düşünme Eğilimi Ölçeği şekillenmiştir. Değişken gruplarını tanımlayıcı kategoriler hâlinde birleştiren faktör analizi, temelde yatan bir kavrama ulaşmak ve yorumları kolaylaştırmak için önemlidir (Yong ve Pearce, 2013). Gerçekleştirilen Cronbach Alpha, Spearman-Brown ve Guttman Split-Half testleri sonuçlarında ölçeğin oldukça güvenilir olduğuna kanaat getirilmiştir. Ölçeğin güvenirliğini sınamak için ortaokul 5-8. sınıflar arasında 90 öğrenciye test-tekrar test uygulaması yapılmıştır. $\mathrm{Bu}$ uygulama sonucunda gerçekleştirilen analizde ölçeğin iç tutarlılık katsayısının iyi düzeyde olduğu tespit edilmiştir. Bu doğrultuda Eleştirel Düşünme Eğilimi Ölçeği'nin yeterli düzeyde iç tutarlılığa sahip olduğu söylenebilir. Bunun ardından ölçeğin bir model olarak doğrulanıp doğrulanmadığını belirlenmesi ve faktör analizi üzerine kurulu hipotezlerin test edilmesi amacıyla DFA yapılmıştır. DFA; ölçüm modelleriyle ilgilenen, 

modelidir ve bir test aracının gizli yapısını incelemek, madde-faktör ilişki modelini doğrulamak için ölçek geliştirme sürecinde kullanılır (Brown ve Moore, 2012). Bu doğrultuda farklı bir örneklem üzerinden 506 ortaokul öğrencisi ile DFA gerçekleştirilmiştir (Çokluk vd. 2018, s. 275). Farklı örneklem grubu ile gerçekleşen bu işlem sonucunda ölçeğin üç faktörlü bir yapıya sahip olduğu doğrulanarak ölçek son hâlini almıştır. Dolayısıyla ortaokul öğrencileri için Eleştirel Düşünme Eğilimi Ölçeği’nin öğrencilerin eleştirel düşünme eğilimlerini belirlemek için saha çalışmalarında kullanılabilecek Likert tipi güvenilir ve geçerli bir ölçme aracı olduğu ifade edilebilir.

\section{Teşekkür ve Bilgilendirme}

Bu araştırma, Fırat Üniversitesi Eğitim Bilimleri Enstitüsü Türkçe Eğitimi Bilim Dalında yürütülen ve 2020 Aralık ayı içerisinde tamamlanan "Ortaokul Öğrencilerinin Eleştirel Düşünme Eğilimleri ile Okuma Becerileri Arasındaki İlişki” adlı yüksek lisans tezinden hareketle oluşturulmuştur. Araştırma süreci boyunca katkı sunan değerli danışman hocam Doç. Dr. Sezgin DEMİR'e teşekkür ederim.

Etik Kurul İzin Bilgisi: Bu araştırma, Fırat Üniversitesi Eğitim Bilimleri Enstitüsü etik kurulunun 17/10/2019 tarihli 97132852 sayll kararl ile alınan izinle yürütülmüştür.

Yazar Çıkar Çatışması Bilgisi: Yazarların beyan edeceği bir çıkar çatışması yoktur.

Yazar Katkısı: Birinci yazar Seyhan YILDIRIM DÖNER; problem durumunun belirlenmesi, literatür taramasının yapılması, verilerin toplanması ve analizi, makalenin tartışma ve raporlama aşamalarında; ikinci yazar Doç. Dr. Sezgin DEMİR; problem durumunun belirlenmesi, araştırma yönteminin belirlenmesi, verilerin toplanması ve analizi ve makalenin gönderim öncesi raporlama ve düzenlenmesi aşamalarında çalışmaya katkı sağlamıştır. 
S, Yıldırım Döner ve S, Demir/ Pamukkale Üniversitesi Eğitim Fakültesi Dergisi, 54, 99-129, 2022

\section{Kaynakça}

Akarsu, B. (2019). Eleştirel düşünme sanatı. İstanbul: Cinius Yayınları.

Akın, A., Hamedoğlu, M. A., Arslan, S., Akın, U., Çelik, E., Kaya, Ç. and Arslan, N. (2015). The adaptation and validation of the Turkish version of the critical thinking disposition scale. The International Journal of Educational Researchers, 6(1), 31-35. https://ijer.penpublishing.net/makale_indir/82

Allahverdi, K. (2009). John Dewey'de eleştirel düşünme yaklaşımı. Yayımlanmamış yüksek lisans tezi. On Sekiz Mart Üniversitesi Sosyal Bilimler Enstitüsü, Çanakkale.

Ay, Ş. ve Akgöl, H . (2008). Eleştirel düşünme gücü ile cinsiyet, yaş ve sınıf düzeyi. Kuramsal Eğitimbilim Dergisi, 1(2), 65-75. Retrieved from https://dergipark.org.tr/en/pub/akukeg/issue/29373/314325

Aybek, B. (2007). Eleştirel düşünmenin öğretiminde öğretmenin rolü. Bilim, Eğitim ve Düşünce Dergisi,7(2). $\quad$ https://docplayer.biz.tr/34954018-Elestirel-dusunmeninogretiminde-ogretmenin-rolu.html

Brown, T. A. and Moore, M. T. (2012). Confirmatory factor analysis. Handbook of structural equation modeling, 361-379.

Can, A. (2018). SPSS ile bilimsel araştırma sürecinde nicel veri analizi. Ankara: Pegem Akademi.

Cüceloglu, D. (2001). İyi düşün doğru karar ver. İstanbul: Sistem Yayıncılık.

Creswell, J. W. (2017). Eğitim araştırmaları: nicel ve nitel araştırmanın planlanması, yürütülmesi ve değerlendirilmesi. (Çev. Edt. Halil Ekşi). İstanbul: EDAM.

Çokluk, Ö., Şekercioğlu, G. ve Büyüköztürk, Ş. (2016). Sosyal bilimler için çok değişkenli istatistik: SPSS ve LISREL uygulamalart. Ankara: Pegem Akademi.

Demir, S. (2019). Dil edinim ve öğretim kuramları ile ilgili temel kavramlar, (Edt. Halit Karatay), Dil eğitiminin temel kavramları. Ankara: Asos Yayınları, s. 261-284.

Demircioğlu, E. (2012). Eleştirel düşünme eğilimi ölçeği'nin uyarlama çalışması ve faktör yapısının farklı değişkenlere göre incelenmesi. Yayımlanmamış yüksek lisans tezi, Abant İzzet Baysal Üniversitesi Eğitim Bilimleri Enstitüsü, Bolu. 
Dilekli, Y. (2019). What are the dimensions of thinking skills in Turkish literature?: A content analysis study. International Journal of Evaluation and Research in Education, 8(1), 110-118. https://files.eric.ed.gov/fulltext/EJ1211267.pdf

Eşel, E. (2005). Kadın ve erkek beyninin farklılıkları. Klinik Psikofarmakoloji Bülteni, 15(3). http://www.psikofarmakoloji.org/pdf/15_3_7.pdf

Facione, P. A. (1990). Critical thinking: A statement of expert consensus for purposes of educational assessment and instruction-The Delphi report. Millbrae, CA: California Academic Press. https://eric.ed.gov/?id=ED315423

Facione, P., Giancarlo, C., Facione, N. and Gainen, J. (1995). The disposition toward critical thinking. Journal of General Education, 44(1), 1-25. DOI: 10.22329/il.v20i1.2254

Fahim, M. and Eslamdoost, S. (2014). Critical thinking: Frameworks and models for teaching. English Language Teaching, 7(7), p141. https://doi.org/10.5539/elt.v7n7p141

Gliem, J. A. and Gliem, R. R. (2003). Calculating, interpreting, and reporting Cronbach's alpha reliability coefficient for Likert-type scales. Midwest Research-to-Practice Conference in Adult, Continuing, and Community Education. http://hdl.handle.net/1805/344

Halpern, D. F. (1998). Teaching critical thinking for transfer across domains: Disposition, skills, structure training, and metacognitive monitoring. American Psychologist, 53(4), 449-455. doi:10.1037/0003-066x.53.4.449

İlhan, M. ve Çetin, B. (2014). LISREL ve AMOS Programları Kullanılarak Gerçekleştirilen Yapısal Eşitlik Modeli (YEM) Analizlerine İlişkin Sonuçların Karşılaştırılması. Ĕ̈itimde ve Psikolojide Ölçme ve Değerlendirme Dergisi, 5(2), Kış 2014, 26-42. Journal of Measurement and Evaluation in Education and Psychology, 5(2), Winter 2014, 26-42.

K1lıç, H. E. ve Şen, A. İ. (2014). UF/EMI eleştirel düşünme eğilimi ölçeğini Türkçeye uyarlama çalışması. Eğitim ve Bilim, $39(176), \quad$ 1-12. http://dx.doi.org/10.15390/EB.2014.3632

Kökdemir, D. (2003). Belirsizlik durumlarında karar verme ve problem çözme. Yayımlanmamış doktora tezi, Ankara Üniversitesi Sosyal Bilimler Enstitüsü, Ankara. 
S, Yıldırım Döner ve S, Demir/ Pamukkale Üniversitesi Eğitim Fakültesi Dergisi, 54, 99-129, 2022

Kökdemir, D. (2012). Üniversite eğitimi ve eleştirel düşünme. PiVOLKA, 21(7), 16-19. https://www.elyadal.org/pivolka/21/PiVOLKA_21_06.pdf

Kurnaz, A. (2007). İlköğretim beşinci sınıf sosyal bilgiler dersinde beceri ve içerik temelli eleştirel düşünme ögrretiminin ögrrencilerin eleştirel düşünme becerileri, erişi ve tutumlarına etkisi. Yayımlanmamış doktora tezi. Selçuk Üniversitesi Sosyal Bilimler Enstitüsü, Konya.

Lawshe, C. H. (1975). A quantitative approach to content validity. Personel Psychology. 28, 563-575. DOI=10.1.1.460.9380

Perkins, D., Jay, E. and Tishman, S. (1993). Beyond abilities: A dispositional theory of thinking. The Merrill-Palmer Quarterly, 39(1), 1-21. https://eric.ed.gov/?id=EJ456333

Piaget, J. (2019). Çocuk psikolojisi. İstanbul: Pinhan Yayıncılık.

Semerci, N. (2016). Eleştirel düşünme eğilimi (EDE) ölçeğinin geliştirilmesi: Geçerlik ve güvenirlik revize çalışması. Turkish Studies, 11(9), 725-740. http://dx.doi.org/10.7827/TurkishStudies.9573

Sönmez, V. ve Alacapınar, F. (2017). Örneklendirilmiş bilimsel araştırma yöntemleri. Ankara: Anı Yayıncılık.

Sümer, N. (2000). Yapısal eşitlik modelleri: temel kavramlar ve örnek uygulamalar. Türk Psikoloji Yazılarl, 3(6), 49-73

Şencan, H. (2005). Sosyal ve davranışsal ölçümlerde geçerlilik ve güvenirlik. Ankara: Seçkin Matbaası.

Tümkaya S. ve Aybek B. (2008). Üniversite öğrencilerinin eleştirel düşünme eğilimlerinin sosyo- demografik özellikler açısından incelenmesi. Çukurova Üniversitesi Sosyal Bilimler Enstitüsü Dergisi, 17(2), 387-402. Retrieved from https://dergipark.org.tr/tr/pub/cusosbil/issue/4379/60056

Walker, S. E. (2003). Active learning strategies to promote critical thinking. Journal of $\begin{array}{llll}\text { athletic } & \text { training, } & 38(3), & \end{array}$ https://www.ncbi.nlm.nih.gov/pmc/articles/PMC233182/ 
128 S, Yıldırım Döner ve S, Demir/ Pamukkale Üniversitesi Eğitim Fakültesi Dergisi, 54, 99-129, 2022

Yong, A. G. and Pearce, S. (2013). A beginner's guide to factor analysis: Focusing on exploratory factor analysis. Tutorials in quantitative methods for psychology, 9(2), 79-94.

Yurdugül, H. (2005). Ölçek geliştirme çalışmalarında kapsam geçerliği için kapsam geçerlik indekslerinin kullanılması. XIV. Ulusal Eğitim Bilimleri Kongresi, 1, 771-774.

Zhang, L. F. (2003). Contributions of thinking styles to critical thinking dispositions. The Journal of Psychology, 137(6), 517-544. DOI: 10.1080/00223980309600633 


\section{Ekler}

\section{Ortaokul Öğrencileri İçin Eleştirel Düşünme Eğilimi Ölçeği}

\begin{tabular}{|c|c|c|c|c|c|}
\hline $\begin{array}{l}\text { Aşağıdaki maddeleri doldururken lütfen elesstirel düsünme eăiliminizi göz önünde } \\
\text { bulundurunuz. Lütfen boşluk bırakmayınız. }\end{array}$ & 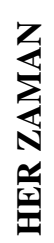 & 光 & $\sum_{\substack{\mathbf{C} \\
\mathbf{S}}}^{\mathrm{Z}}$ & $\frac{\mathbf{a}}{\frac{\mathbf{a}}{\mathbf{a}}}$ & $\cdot \underline{\underline{Z}}$ \\
\hline 1. Çevremdeki insanların fikirlerini dikkatlice dinlerim. & 5 & 4 & 3 & 2 & 1 \\
\hline 2. İnsanların fikirlerini oluşturan nedenleri önemserim. & 5 & 4 & 3 & 2 & 1 \\
\hline 3. Problemlere ürettiğim çözümleri paylaşırken kendime güvenirim. & 5 & 4 & 3 & 2 & 1 \\
\hline 4. Karşıt fikirleri değerlendirirken tarafsız davranırım. & 5 & 4 & 3 & 2 & 1 \\
\hline 5. Bir durumu tüm yönleri ile tanımlayabilirim. & 5 & 4 & 3 & 2 & 1 \\
\hline 6. Fikirlerimin arkasında durabilirim. & 5 & 4 & 3 & 2 & 1 \\
\hline 7. Bir probleme getirdiğim çözümün neden doğru olduğunu açıklayabilirim. & 5 & 4 & 3 & 2 & 1 \\
\hline 8. Bilgiyi edinmeye meraklıyımdır. & 5 & 4 & 3 & 2 & 1 \\
\hline 9. Kendi düşüncelerimin farkındayımdır. & 5 & 4 & 3 & 2 & 1 \\
\hline 10. İnsanlarla herhangi bir konu üzerinde tartışmalarda bulunmayı severim. & 5 & 4 & 3 & 2 & 1 \\
\hline 11. Bir cümledeki ön yargıyı sezebilirim. & 5 & 4 & 3 & 2 & 1 \\
\hline 12. Bir olayın temelindeki nedenleri keşfetmek benim için önemlidir. & 5 & 4 & 3 & 2 & 1 \\
\hline 13. Çevremdeki insanların fikirlerini tarafsız bir şekilde dinlerim. & 5 & 4 & 3 & 2 & 1 \\
\hline 14. Problem çözme konusunda kendime güvenirim. & 5 & 4 & 3 & 2 & 1 \\
\hline 15. Mantık hatalarını tanımlayabilirim. & 5 & 4 & 3 & 2 & 1 \\
\hline 16. Düşünce sürecimde temel amacım doğrulara ulaşmaktır. & 5 & 4 & 3 & 2 & 1 \\
\hline 17. Olayların detaylarına odaklanabilirim. & 5 & 4 & 3 & 2 & 1 \\
\hline 18. Eleştirel düşünmeyi severim. & 5 & 4 & 3 & 2 & 1 \\
\hline 19. Günlük hayatta eleştirel düşünmeye başvururum. & 5 & 4 & 3 & 2 & 1 \\
\hline 20. Eleştirel düşünme benim için önemlidir. & 5 & 4 & 3 & 2 & 1 \\
\hline 21. Eleștirel düșünmenin bana katkı sağladığını düșünüyorum. & 5 & 4 & 3 & 2 & 1 \\
\hline
\end{tabular}

Diyalektik Düşünme (12 madde): m1, m2, m3, m5, m6, m7, m8, m9, m12, m14, m16, m17.

Eğilim (4 madde): m18, m19, m20, m21.

Analiz (5 madde): m4, m10, m11, m13, m15.

Ölçekte ters döndürülmesi gereken bir madde yoktur.

İkinci düzey DFA'sı yapıldığı için ölçek, genel puanı üzerinden de analizlerde kullanılabilir. 


\title{
Developing the Critical Thinking Disposition Scale for Secondary School Students: a Validity and Reliability Study*
}

\author{
Seyhan YILDIRIM DONER ${ }^{* *}$ Sezgin DEMIR ${ }^{* * *}$
}

• Received: 09.11.2020 • Accepted: 17.06.2021 • Online First: 17.06.2021

\begin{abstract}
Critical thinking disposition; expresses individuals' orientation towards using skills within the scope of critical thinking, such as analysis, evaluation, interpretation, and discussion. This study aims to develop a valid and reliable Critical Thinking Disposition Scale for secondary school 5th, 6th, 7th, and 8th-grade students (9-14 years old). A different sample group has been selected for exploratory factor analysis, test-retest, and confirmatory factor analysis, each time using the simple random sampling method. Cronbach's Alpha value has been determined as .87, Spearman-Brown and Guttman split-half value as .81 in the reliability analysis performed on the obtained data, and it has been found that the scale was quite reliable. It has been found that the scale also had internal consistency in test-retest applications. The internal consistency coefficient of .75 indicates that the consistency of the scale is high as a result of the test-retest. As a result of the exploratory factor analysis, the scale's 21-item three-factor scale structure, which has a total variance value of $42.94 \%$, has been confirmed by confirmatory factor analysis $\left(\mathrm{X}^{2}=345.18\right.$, sd $=184 \mathrm{RMSEA}=.042, \mathrm{NFI}=$ $.97, \mathrm{NNFI}=.98, \mathrm{CFI}=.99 ., \mathrm{GFI}=.88, \mathrm{AGFI}=.85, \mathrm{SRMR}=.059)$. The construct reliability of the scale has been calculated as 93 , and it has been concluded that the scale was reliable enough. As a result of the research, it can be stated that a valid and reliable Likert-type scale with 21 items and three dimensions has been introduced to the literature.
\end{abstract}

Keywords: critical thinking disposition, secondary school students, scale, validity, reliability.

Cited:

Yıldırım Döner, S., \& Demir, S. (2022) Developing the critical thinking disposition scale for secondary school students: A validity and reliability study. Pamukkale University Journal of Education, 54, 99-129. doi: 10/9779.pauefd.823427.

\footnotetext{
* This study was created on the basis of her master's thesis "The Relationship Between Middle School Students' Critical Thinking Disposition and Reading Skills".

** Master of Science, Firat University, seyhanyldrm08@gmail.com, ORCID: 0000-0002-6778-4925

*** Assoc. Prof., Firat University Faculty of Education Turkish Education Department, sezgin.demir@ firat.edu.tr, ORCID: 0000-0002-0466-2218
} 


\section{Introduction}

Thinking is a skill that develops dynamically, changes and can be taught. The thinking process is a process that does not have a beginning or has no starting time, and that should usually start with focus and end with association (Akarsu, 2019). Thinking has its own specific skill areas. Costa ( 2001 as cited in Dilekli, 2019) gathered his thinking skills under 4 main headings: critical thinking, problem solving, decision making, creative thinking. Critical thinking is a thinking that occurs as a result of many mental processes and activities such as defining, analyzing, evaluating, interpreting. Ennis (cited in 1986. Kurnaz, 2007) defined the concept of critical thinking as rational and deep thinking in the decision-making process of what an individual does and believes. Bloom (as cited in 1956 by Fahim and Eslamdoost, 2014) stated that critical thinking is necessary for all skills in the stages of Bloom's Taxonomy and especially analysis, synthesis and evaluation are generally directed towards critical thinking. Critical thinking is an active mental process in which the individual is aware of his / her thought processes, makes sense of the events that take place in line with what they have learned, and aims to do this (Cüceloğlu, 2001).

Being aware of one's own thoughts and biases, and being able to look at the situations and problems they encounter from a multiple perspective are important elements of critical thinking (Kökdemir, 2012).

The concept of critical thinking has two main dimensions: skill and disposition (Halpern, 1993, Facione, 1990, p. 3). Disposition is defined as the desire for an area, situation or behavior, the disposition to do it, and also the disposition to use existing skills (Facione, Giancarlo, Facione, \& Gainen, 1995). Dispositions are about skills and lead to the use of skills (Perkins, Jay, \& Titman, 1993). Critical thinking disposition is the actual orientation towards critical thinking and using critical thinking skills. In order to use critical thinking skills, there must also be a disposition towards critical thinking (Facione, Giancarlo, Facione, \& Gainen, 1995). Many researchers advocate that existing critical thinking skills can be used when critical thinking disposition is present (Halpern, 1998; Walker, 2003; Zhang, 2003). The skill becomes blunt because it cannot be used when there is no disposition. For this reason, it was stated that it would not be enough to teach the skill alone, the important thing was to create a disposition to make the desire to use the skill (Halpern, 1998). Facione, Facione and Giancarlo divided critical thinking disposition into 7 characteristics in their study: 


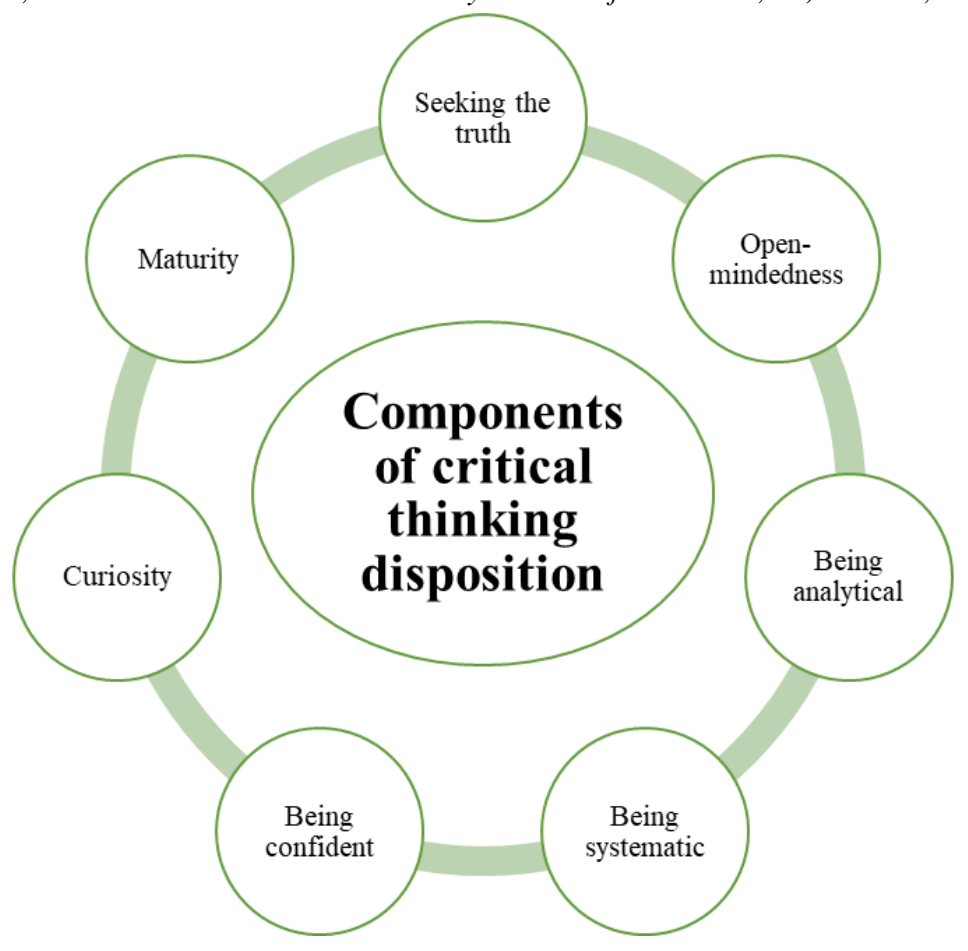

Figure 1. Theory of critical thinking (Adapted from Faccione P., Faccione N., \& Giancarlo, 2000.)

Some factors affect individuals' critical thinking disposition in many ways. These factors play a role in forming and developing both critical thinking skills and critical thinking disposition. One of the factors affecting critical thinking disposition is gender. The gender factor is important as it is assigned different roles in every society and creates biological and psychological differences. Gender roles are those that are determined by the society and whose limits are drawn by the society. If a skill is not considered suitable for a gender group in society, that gender group may be affected positively or negatively in acquiring or using that skill. For example, in some societies, especially women are less recognized than men and women are prevented from criticizing and expressing their criticism. In such societies, it is natural for female gender groups to be negatively affected by the gender role in terms of critical thinking disposition. Studies have shown that the gender factor causes differences in biological and psychological dimensions. Eşel (2005) examined the brains of men and women in terms of understanding emotions, perception, speaking ability, spatial and mathematical abilities, memory and attitude and found that women were more successful than men in the areas of understanding emotions, perception speed, speaking ability, verbal memory; he found that men are more successful in spatial abilities, there is an uncertain situation in mathematical abilities, and that men and women are completely different in some areas in their attitudes towards life. Apart from this, it can 
be said that the age of individuals affects their critical thinking disposition in terms of their physical, mental, cognitive, affective, psychological, etc., development. For example, Piaget (2019, p.36) stated that perceptual activities depend on quantity and quality and develop with age. In their study, Ay and Akgöl (2008) stated that age level affects critical thinking power. It can be said that the age level plays a role in critical thinking as it brings along many maturities. Another factor examined in the literature is the individual's behaviors, beliefs, and attitudes towards the critical thinking skills of the parents. In the study of Tümkaya and Aybek (2008), it was seen that the individual spends the most time and the education status of the mother, who takes the most example even while learning the language, significantly differentiates the individual's critical thinking disposition. Therefore, the authoritarian, protective, or democratic attitude of the mother and father at home can determine how much an individual has a voice in the home environment and how much attention is paid to his or her thoughts. In addition, it can be said that the teacher and the school factor play a role in shaping the individual's critical thinking disposition. The school and the teacher factor are responsible for the development of the students they train for education and training and the acquisition of the necessary gains. Therefore, their understanding of education and creating a school and classroom environment that will support the student in critical thinking may play a role in forming the disposition. To raise critical and questioning individuals, teachers should have these qualities and know how to teach them to students (Aybek, 2007). Apart from these, the individual's perceived personality traits, socio-economic level, academic success, society, and culture in which he/she lives can be counted among the factors affecting critical thinking disposition.

These factors, which affect critical thinking disposition, have become an important concept in the education process of the individual. As a result of the acquisition of this disposition to individuals in the educational process, it can be said that these individuals can be successful thanks to the critical thinking disposition in the skills that are expressed throughout their lives. In line with the development of critical thinking disposition in language and thinking skills, it must be present, especially in secondary school students who are taught gradually. Because language and thinking skills are explained beyond the impression method at the secondary school level, and they are taught by giving students a consciousness. In other words, situations such as how much the student grasps the critical thinking disposition at the secondary school level, whether he/she has this disposition will also be effective in his / her gaining language and thinking skills. When the literature was 
examined, it was observed that the critical thinking disposition scales developed differed in the sample groups but were not directly aimed at secondary school students. In this respect, it was thought that including a critical thinking disposition scale for secondary school students in the literature would be useful for measuring students' critical thinking disposition levels. The Critical Thinking Disposition (EDE) Scale, developed by Semerci (2016), is designed for prospective teachers and teachers; UF / EMI Critical Thinking Disposition Scale adapted into Turkish by Ertaş Kılıç, and Şen (2014) is designed for high school students; The Critical Thinking Disposition Scale, which was adapted to Turkish by Demircioğlu (2012) and developed by Ricketts and Rudd in 2005, is designed for high school students; The Critical Thinking Disposition Scale developed by Akın et al. (2015) is designed for university students; California Critical Thinking Disposition Scale, which was adapted to Turkish by Kökdemir (2003), is applied to university level students. As can be seen, there is a lack of scales for secondary school students in the literature. For this reason, it is thought that a critical thinking disposition scale for secondary school students (9-14 years old) will contribute to the literature. In this direction, the study aims to develop a valid and reliable Critical Thinking Disposition Scale that will determine secondary school students' critical thinking disposition levels.

\section{Method}

The research was carried out in the quantitative research type, in the scanning model. Measurement is the classification, ranking, spacing or proportional explanation of the qualities possessed by individuals or objects through a tool (Büyüköztürk, Kılıç Çakmak, Akgün, Karadeniz, \& Demirel, 2018, p.106-107). The measurement concept is important, and the concepts of reliability and validity can be generalized since the data obtained from measurement tools in quantitative research (Sönmez \& Alacapınar, 2017, p.187). During the scale development process, in the light of those as mentioned earlier, first, the problem is defined, the items for the scale are written based on the literature, then the pre-application is made by taking the expert opinion, finally, the necessary analyzes are made, and the scale is finalized (Büyüköztürk et al. 2018, p.130-140). Likert-type scales are theoretically considered to be equally spaced between answers (Creswell, 2017).

\section{Population and Sample}

The research universe consists of secondary school students studying at public schools in the 2019-2020 academic year. Since it was not considered possible to reach the target population, the state secondary school students in the city center of Tokat have been 
determined as the accessible population. While developing the measurement tool, different sample groups from the population determined in each analysis were used. First of all, the names of the state schools in Tokat city center were written on paper and placed in a bag. Schools selected for the first stage of the scale were randomly selected from this bag. After the first school where the application will take place was selected in this way, the paper of the determined school was put back in the bag, and the second school was selected with the same method. The class and branch information of the selected secondary schools were obtained, and the grade levels and branches of each school were written on papers as 5th, 6th, 7th, and 8th grades and placed in separate bags. In the selection that took place separately for each grade level, two different branches were determined at each grade level within the 9-14 age group of each school. Thus, the first scale application, the exploratory factor analysis (EFA), was carried out on 503 students, including two schools, 4-grade levels (5-8), 16 class classes.

Then, for the test-retest application of the scale, state schools in the city center of Tokat were rewritten on paper and put in a bag, and a different secondary school was selected by the random selection method. In the designated school, one branch from the 5th, 6th, 7th, and 8th grades was selected by cluster sampling method, and 2 separate applications were carried out at 15 days intervals in these branches. One hundred twenty-two students were reached in the first application and 112 students in the second. Later, the analysis was carried out for over 90 students, with only those who participated in the first or second application and the students who filled the form sloppy with invalid forms.

Finally, for the confirmatory factor analysis (CFA), which will ensure the model fit of the scale, the simple random sampling method was applied again, and a secondary school in Tokat city center was determined by random selection among the papers in the bag. In this school, 4 branches were selected from each grade level as 5, 6, 7, and 8 by cluster sampling method, and this application of the scale was carried out on 506 students in total. While determining schools and branches, simple random sampling and cluster sampling method was used each time. In each analysis of the study, care was taken to collect data from a different sample group. Accordingly, different research applications were carried out in 2 secondary schools for EFA, 1 for test-retest analysis and 1 for DFA.

\section{Procedure}

Researchers developed the Critical Thinking Disposition Scale to measure the level of critical thinking dispositions of secondary school students. For the scale development study, 
S. Y1ldırım Döner, \& S. Demir / Pamukkale University Journal of Education, 54, 99-129, 2022

wide-ranging literature was first carried out, and an item pool of 43 items was created for critical thinking disposition suitable for secondary school students. The Lawshe Technique (1975) was used to ensure the content validity of these created items, and in this context, the content validity ratio (CVR) was calculated by submitting the scale draft to expert opinions. A total of 8 academicians, including 6 Turkish language education and 2 educational sciences, were consulted, and it was taken into consideration that the significance value of the content validity index within the scope of the Lawshe Technique should be at least .78 in 8 expert opinions (Yurdugül, 2005). Experts were asked to express their opinions as "necessary, corrected, removed" for each item, and the content validity index of the items in the scale draft was calculated as .78 in line with the opinions obtained, due to the statistical significance of the determined value and providing the content validity index. Apart from this, the experts' opinions who chose the "must be corrected" option in the items and made suggestions for the correction were taken into consideration, and the scale was shaped accordingly.

After obtaining official permissions, the first application of the draft scale was carried out in 2 secondary schools determined by simple random sampling in the city center of Tokat in accordance with the formula "number of items $\times 10(43 \times 10=430)$ " at the 5 th and 8th grades, in two branches each determined by cluster sampling method. It was carried out with 504 students. An exploratory factor analysis was performed to obtain evidence for the construct validity of the data transferred to the SPSS program and to verify the factor structure (Çokluk, Şekercioğlu, \& Büyüköztürk, 2018). In order to measure the construct validity, the Kaiser-Meyer-Olkin (KMO) test and Barlett sphericity test were applied to determine whether factor analysis can be performed on the data and test the suitability of the sample size factoring. In order to measure the internal consistency, Cronbach's Alpha reliability analysis was performed on the whole scale over the data obtained in the draft scale application. Then, Cronbach's Alpha test was conducted for each sub-dimension of the scale, and the level of correlation of each factor in its own items was checked. The effect of scale items on total variance and scale means item eigenvalues, corrected item-total correlation, and reliability values of the scale were examined.

In order to make the Critical Thinking Disposition Scale for Secondary School Students more reliable and to demonstrate its structural validity by ensuring the calculated reliability, test-retest was applied to one branch at the 5th, 6th, 7th, and 8th grades in another school in the city center of Tokat determined by simple random sampling method. The data 
obtained were transferred to the computer environment through the SPSS program, and as a result of the analysis of the test-retest application, the internal consistency coefficient of the scale was found to be " $r=.75 "$ within the scope of good reliability. Accordingly, it was decided that the Critical Thinking Disposition Scale had sufficient internal consistency. Confirmatory factor analysis was decided to test whether the Critical Thinking Disposition Scale for Secondary School Students was verified as a model and the hypotheses based on factor analysis (Çokluk et al., 2018, p.275). CFA was carried out on 506 students studying in 4 branches, determined by cluster sampling in each of the 5th and 8th grades in a different secondary school selected by a simple random sampling method in the city center of Tokat. The data obtained were transferred to the computer environment, and the CFA application was carried out through the LISREL program. Model fit measures of the scale were revealed by using chi-square $\left(\mathrm{X}^{2}\right)$ value, the ratio of chi-square value to df, RMSEA, Standardized RMR, NFI, NNFI, CFI, GFI, and AGFI values in the model fit of the scale (Çokluk, Şekercioğlu, Büyüköztürk, 2012 ). As a result of the CFA, it was seen that the model achieved perfect fit in CFI, NFI, NNFI (TLI), RFI, IFI, RMSEA values, and acceptable/good fit in AGFI, GFI, SRMR, PNFI, and PGFI values (Sümer, 2000, p.68; Brown 2016 " cited from Çokluk, Şekercioğlu, Büyüköztürk, 2012, p. 272).

\section{Findings}

In this section, the findings obtained as a result of the research are tabulated and explained concerning the literature.

\section{Exploratory Factor Analysis}

In order to determine the structure of the scale and reveal the construct validity, an exploratory factor analysis (EFA) was performed on the data obtained after the preapplication. With EFA, the factor structure and items of the scale were determined, and it was determined whether it provided the construct validity or not.

Table 1. KMO and Bartlett's Test of the Critical Thinking Disposition Scale for Secondary School Students

\begin{tabular}{lcc}
\hline Kaiser-Meyer-Olkin Measure of Sampling Adequacy & .938 \\
Barlett's Test of Sphericity & Approx. Chi-Square & 6125.515 \\
& df & 903 \\
& sig & .000 \\
\hline
\end{tabular}


The KMO value of the scale was determined to be .94 in the tests conducted to determine whether EFA can be performed on the data and to test the suitability of the sample size for factorization. Since this value is above .90 , it can be said to be at an "excellent" level (Jackson \& Holland, cited in 2003. Şencan, 2005, p. 384). Then, factor analysis was performed since it was seen in the Barlett Test of Sphericity that the sig value was .000 and that the obtained chi-square value was significant $(\chi 2(903)=6125.515 ; \mathrm{p}<.01)$.

In order to reveal the factor pattern of the scale, principal component analysis was determined as the factoring method, and maximum variability (varimax), one of the orthogonal rotation methods, was determined as the rotation method.

As a result of the analysis, it was seen that the relationship between the 43 items taken as the basis of the analysis was $r>.30$, and the matrix determinant value was greater than .0001 . Since multiple collinearities ( $r>.80)$ were not detected between the items and the intersection values of the items in the anti-image correlation matrix were above .50 , the item was not removed from the scale. In the resulting component matrix, it was determined that the first-factor load value of 43 items in the measurement tool was .458 and above. 9 factors with eigenvalues above one were determined for 43 items that were taken as the basis of the analysis. It was seen that the contribution of these factors to the variance was \%49.396. In order to decide the number of factors, the total variance values of the factors were examined, and it was determined that the first two components contributed to the variance, and after the third component, the contribution to the variance gradually decreased. Accordingly, although it was thought that 2 or 3 factors could be determined for the scale, it was found useful to examine the scree plot.

In the figure, it is seen that the components are descending towards the $\mathrm{X}$-axis. Since each of the breaks between two points means a factor, it has been confirmed that the contribution of the components to the variance decreases and becomes the same after the third point. The researchers decided the factor number was decided to be three by researchers because it was compatible with the scree plot. After this stage, the normal value was entered as .33 in order to see the items that can explain the variance of at least $\% 10$ under each factor for multifactorial EFA (Can, 2018). 


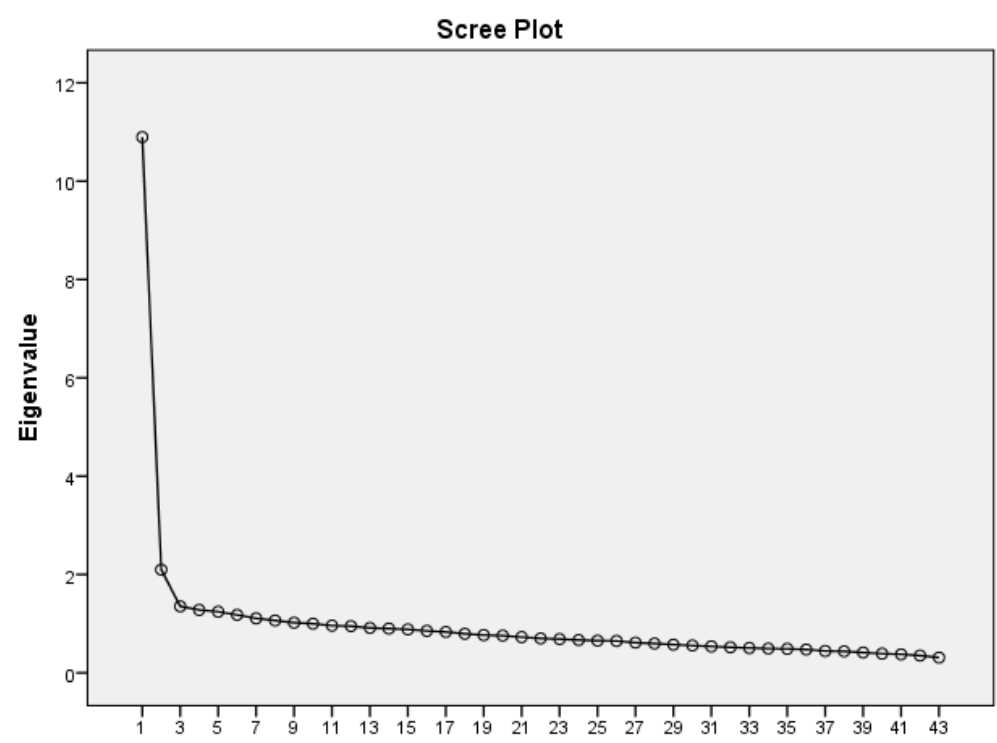

Figure 1. Scree-puddle plot regarding the number of factors

After deciding the number of factors, rotation was performed. In the resulting rotated components matrix, items with an association level below .33 were removed one by one, respectively, and the analysis was repeated each time. In this process, items i5, i6, i16, i23, $i 30, i 34, i 37, i 42, i 43$ were removed from the scale because they were unloaded $(r<.33)$. Since the item associated with more than one factor was not seen, no item was accepted as an overlapping item. Then, the factor analysis of the scale was re-performed by entering the value ". 45 " in order to strengthen the factor structures. As a result of this process, items i1, i2, i8, i9, i10, i11, i14, i18, i19, i24, i31, i36 below the value of ".45" ( $r<.45)$ were also removed from the scale. Although the $22 \mathrm{nd}$ item has a load value of .56 in the Rotated Component Matrix, it was removed from the scale to ensure conceptual consistency based on the literature. 
S. Yıldırım Döner, \& S. Demir / Pamukkale University Journal of Education, 54, 99-129, 2022

Table 2. Critical Thinking Disposition Scale for Secondary School Students factor analysis results

\section{After Rotation}

Items Common Variance

$$
1^{\text {st }} \text {-factor load } \quad 2^{\text {nd }} \text {-factor load } \quad \begin{gathered}
3^{\text {rd }} \text {-factor } \\
\text { load }
\end{gathered}
$$

\begin{tabular}{|c|c|c|c|c|}
\hline I15 & .423 & .628 & & \\
\hline I29 & .411 & .597 & & \\
\hline I17 & .427 & .585 & & \\
\hline I7 & .353 & .572 & & \\
\hline I21 & .416 & .565 & & \\
\hline I3 & .361 & .549 & & \\
\hline I35 & .330 & .547 & & \\
\hline I27 & .382 & .530 & & \\
\hline I13 & .322 & .518 & & \\
\hline I33 & .421 & .508 & & \\
\hline $\mathrm{I} 20$ & .310 & .506 & & \\
\hline I4 & .325 & .502 & & \\
\hline I40 & .673 & & .788 & \\
\hline I41 & .603 & & .755 & \\
\hline $\mathrm{I} 38$ & 619 & & .755 & \\
\hline I39 & .627 & & .753 & \\
\hline I12 & .473 & & & 687 \\
\hline I32 & .466 & & & 609 \\
\hline $\mathrm{I} 28$ & .382 & & & .569 \\
\hline I26 & .410 & & & .562 \\
\hline $\mathrm{I} 25$ & .284 & & & .458 \\
\hline
\end{tabular}


In the explained total variance table, it was determined that all scale items met the acceptance level of the values (.45). As a result, 21 items remained in the Critical Thinking Disposition Scale for secondary school students. Then, the 3-factor structure determined by analysis was named in accordance with the literature. This factor was named dialectical thinking because the items in the 1st factor were items for reasoning based on opposing situations and measuring the student's disposition to reach his synthesis (eg, my main goal in my thought process is to reach the truths). This factor was named disposition because the items in the 2nd factor directly measure the individual's critical thinking disposition (e.g. I like to think critically). Since the items in the 3rd factor measure the disposition towards analysis and evaluation in the individual (e.g., I can sense bias in a sentence), this factor is called analysis. Twelve items (i15, i29, i17, i7, i21, i3, i35, i27, i13, i33, i20, i4) under the 1st factor (Dialectical Thinking), four items (i40, i41, under the 2nd factor (Disposition) i38, i39), and under the 3rd factor (Analysis) there are five items (i12, i22, i38, i26, i25).

When the total variance table explained was examined, the total variance for the 1st factor was $\% 18.9$, the total variance for the 2 nd factor was $12.4 \%$, and the total variance for the 3rd factor was \%11.60. In total, it was found that the ratio of explaining the variance by the three factors was \%42.94. Based on the information that the cumulative value should be at least \%40 in multidimensional scales, it can be said that factor analysis is acceptable.

\section{Reliability Analysis}

Cronbach's Alpha, Spearman-Brown, and Guttman Split-Half reliability coefficients were calculated for Cronbach in order to determine the validity and reliability coefficient of the Critical Thinking Disposition Scale:

Table 3. Cronbach's Alpha, Spearman-Brown, Guttman split-half Reliability Test

\begin{tabular}{lcccc}
\hline \multicolumn{1}{c}{ Scale } & $\begin{array}{c}\text { Cronbach's } \\
\text { Alpha } \\
\text { Coefficient }\end{array}$ & $\begin{array}{c}\text { Spearman-Brown } \\
\text { Coefficient }\end{array}$ & $\begin{array}{c}\text { Guttman split-half } \\
\text { Coefficient }\end{array}$ \\
\hline $\begin{array}{l}\text { Critical } \\
\text { Disposition Scale }\end{array}$ & Thinking & .868 & .805 & .805 \\
\hline
\end{tabular}

The reliability coefficient of the scale takes a value between -1 and +1 , but the closer it is to +1 , the more reliable it is (Can, 2018). Cronbach's Alpha value was determined as .87 due to the reliability test applied to the Critical Thinking Disposition Scale for secondary 
S. Yıldırım Döner, \& S. Demir / Pamukkale University Journal of Education, 54, 99-129, 2022

school students. This value has been determined as "highly reliable" in the categories of Cronbach's Alpha reliability coefficient values. . $00 \leq \alpha<.40=$ unreliable, $.40 \leq \alpha<.60=$ lowly reliable, $.60 \leq \alpha<.90=$ highly reliable, $.90 \leq \alpha<1.00=$ considered highly reliable (George and Mallery, as cited in 2003. Gliem and Gliem, 2003). In order to ensure the reliability of the scale, in addition to Cronbach's Alpha test, Spearman-Brown and Guttman Split-Half reliability tests were applied throughout the scale. Spearman-Brown and Guttman Split-Half reliability coefficients were calculated as ".81," and these values were found to be quite reliable.

Table 4. Reliability coefficients for scale items

\begin{tabular}{|c|c|c|c|c|c|}
\hline & $\begin{array}{l}\text { Scale Mean if } \\
\text { Item Deleted }\end{array}$ & $\begin{array}{l}\text { Scale Variance } \\
\text { if Item Deleted }\end{array}$ & $\begin{array}{l}\text { Corrected Item- } \\
\text { Total Correlation }\end{array}$ & $\begin{array}{c}\text { Squared } \\
\text { Multiple } \\
\text { Correlation }\end{array}$ & $\begin{array}{l}\text { Cronbach Alfa } \\
\text { if Item Deleted }\end{array}$ \\
\hline $\mathrm{I} 3$ & 77.1885 & 144.809 & .455 & .293 & .859 \\
\hline I4 & 77.5079 & 143.749 & .435 & .272 & .860 \\
\hline I7 & 77.2679 & 144.964 & .452 & .265 & .859 \\
\hline $\mathrm{I} 12$ & 77.7937 & 145.607 & .315 & .189 & .865 \\
\hline I13 & 77.8016 & 144.291 & .462 & .273 & .859 \\
\hline I15 & 77.0456 & 147.185 & .399 & .234 & .861 \\
\hline I17 & 77.4008 & 141.843 & .549 & .347 & .856 \\
\hline $\mathrm{I} 20$ & 77.1687 & 145.361 & .440 & .241 & .860 \\
\hline $\mathrm{I} 21$ & 77.0853 & 144.599 & .516 & .333 & .858 \\
\hline $\mathrm{I} 25$ & 77.7540 & 143.426 & .398 & .198 & .862 \\
\hline I26 & 77.6151 & 142.734 & .479 & .272 & .858 \\
\hline $\mathrm{I} 27$ & 77.5536 & 142.474 & .510 & .348 & .857 \\
\hline $\mathrm{I} 28$ & 77.4306 & 144.926 & .414 & .218 & .861 \\
\hline
\end{tabular}




\begin{tabular}{cccccc}
\hline & $\begin{array}{c}\text { Scale Mean if } \\
\text { Item Deleted }\end{array}$ & $\begin{array}{c}\text { Scale Variance } \\
\text { if Item Deleted }\end{array}$ & $\begin{array}{c}\text { Corrected Item- } \\
\text { Total Correlation }\end{array}$ & $\begin{array}{c}\text { Squared } \\
\text { Multiple } \\
\text { Correlation }\end{array}$ & $\begin{array}{c}\text { Cronbach Alfa } \\
\text { if Item Deleted }\end{array}$ \\
\hline I29 & 77.3214 & 143.873 & .485 & .309 & .858 \\
I32 & 77.7202 & 142.242 & .500 & .309 & .858 \\
I33 & 77.3671 & 142.467 & .521 & .371 & .857 \\
I35 & 77.3909 & 145.734 & .436 & .239 & .860 \\
I38 & 77.7560 & 141.056 & .470 & .409 & .859 \\
I39 & 78.0000 & 143.487 & .395 & .373 & .862 \\
I40 & 77.8849 & 141.796 & .453 & .465 & .859 \\
I41 & 77.8036 & 142.353 & .435 & .395 & .860 \\
\hline
\end{tabular}

When the corrected item-total correlation coefficient resulting from the Cronbach's Alpha test was performed, it was seen that no item was below .20, and therefore, no item was removed from the scale. It is seen that the corrected item-total correlation coefficients in the whole of the scale are above .30, and therefore item reliability is at a good level. For the corrected item-total correlation coefficient, 30 and above items are considered good items, items between 20 and 30 are considered items that can be taken if necessary or necessary for the measurement tool, items below 20 are considered items that should be removed from the scale (Can, 2018, p.392).

Table 5. Cronbach's Alpha Reliability Test for sub-dimensions

\begin{tabular}{lccc}
\hline \multicolumn{1}{c}{ Sub-dimensions } & $\begin{array}{c}\text { Cronbach's } \\
\text { Alpha }\end{array}$ & $\begin{array}{c}\text { Cronbach Alfa } \\
\text { Based on } \\
\text { Standardized Items }\end{array}$ & N of Items \\
\hline Dialectical Thinking & .833 & .833 & 12 \\
Disposition & .800 & .800 & 4 \\
Analysis & .642 & .647 & 5 \\
\hline
\end{tabular}


As a result of the reliability test applied to the first factor of the scale, Cronbach's Alpha value was found as .83. This value has been determined to be quite reliable in the categories of Cronbach's Alpha reliability coefficient values. It was seen that all the coefficients of the factor items were above .30. As a result of the Cronbach's Alpha test applied to the second factor, it is seen that the items in the factor have a relationship level between 58 and 65 . The item was not removed because the factor items were at the level of good items. As a result of the reliability test applied to the second factor of the scale, Cronbach's Alpha value was determined as .80. This value has been determined to be quite reliable in the categories of Cronbach's Alpha reliability coefficient values. As a result of the Cronbach's Alpha test applied to the third factor, it is seen that the items in the factor have a relationship level above .30 . The item was not removed because the factor items were at the level of good items. As a result of the reliability test applied to the third factor, Cronbach's Alpha value was determined as .64. This value has been determined to be quite reliable in the categories of Cronbach's Alpha reliability coefficient values.

\section{Test-Retest Application}

In order to make the Critical Thinking Disposition Scale more reliable and to ensure the calculated reliability, the test-retest application was applied to one branch at the 5th, 6th, 7th and 8th grades in a school determined by random sampling method in the city center of Tokat.

Table 6.Test-Retest correlation analysis

\begin{tabular}{|c|c|c|c|c|c|}
\hline & & Test & Retest & Mean & $\begin{array}{l}\text { Standard } \\
\text { deviation }\end{array}$ \\
\hline \multirow{3}{*}{ Test } & $\begin{array}{l}\text { Pearson } \\
\text { correlation }\end{array}$ & 1.000 & $.748 * *$ & \multirow{3}{*}{3.86} & \multirow{3}{*}{.55} \\
\hline & Sig (2-tailed) & & .000 & & \\
\hline & $\mathrm{N}$ & 90 & 90 & & \\
\hline \multirow{3}{*}{ Retest } & $\begin{array}{l}\text { Pearson } \\
\text { correlation }\end{array}$ & $.748 * *$ & 1.000 & \multirow{3}{*}{4.02} & \multirow{3}{*}{.56} \\
\hline & Sig (2-tailed) & .000 & & & \\
\hline & $\mathrm{N}$ & 90 & 90 & & \\
\hline
\end{tabular}


As a result of the test-retest application analysis, the scale's internal consistency coefficient was found to be .75 within the scope of good reliability and this value was found to be significant at the .01 level. Accordingly, it was decided that the Critical Thinking Disposition Scale has a very strong level of internal consistency. Since there is no other scale in the literature based on critical thinking disposition for secondary school students, no application has been made regarding the criterion validity. However, expert opinions were taken from the faculty members in the Turkish Education Department at Firat University and Amasya University. For this reason, the test-retest application was applied. In addition, in the second-level multifactorial confirmatory factor analysis application performed on a different sample, the measurement model fit indexes were found to be perfect.

\section{Confirmatory Factor Analysis}

In order to test whether the Critical Thinking Disposition Scale was verified as a model and the hypotheses based on factor analysis, the scale was subjected to confirmatory factor analysis through a different sample (Çokluk et al., 2018). DFA of the three-factor scale was carried out on 21 items obtained with EFA. In order to test the model fit of the Critical Thinking Disposition Scale, "second-level CFA" was carried out over 21 items using the LISREL 8.80 program. During CFA, the "weighted least squares estimation method" was used.

Table 7. The measurement model obtained as a result of the second level confirmatory factor analysis for the Critical Thinking Disposition Scale

\begin{tabular}{lccccc}
\hline Factor & Items & $\begin{array}{c}\text { Error } \\
\text { Variance }\end{array}$ & Standardized Loads & t-value & $\mathrm{R}^{2}$ \\
\hline & I6 & .60 & .63 & .40 \\
Dialectical & I1 & .69 & .55 & 10.63 & .31 \\
Thinking & I3 & .67 & .57 & 10.29 & .33 \\
& I5 & .69 & .60 & 9.97 & .36 \\
& I7 & .47 & .56 & 10.97 & .31 \\
& & & .72 & 7.51 & .53
\end{tabular}




\begin{tabular}{|c|c|c|c|c|c|}
\hline Factor & Items & $\begin{array}{c}\text { Error } \\
\text { Variance }\end{array}$ & Standardized Loads & t-value & $\mathrm{R}^{2}$ \\
\hline & I8 & .69 & .56 & 10.49 & .31 \\
\hline & I9 & .67 & .57 & 10.24 & .33 \\
\hline & $\mathrm{I} 12$ & .64 & .60 & 10.06 & .36 \\
\hline & I14 & .53 & .69 & 8.01 & .47 \\
\hline & I16 & .65 & .69 & 9.63 & .35 \\
\hline & I17 & .54 & .60 & 8.43 & .46 \\
\hline \multirow{4}{*}{ Disposition } & $\mathrm{I} 20$ & .26 & .86 & & .74 \\
\hline & I18 & .47 & .73 & 7.22 & .53 \\
\hline & I19 & .33 & .82 & 5.49 & .67 \\
\hline & $\mathrm{I} 21$ & .38 & .79 & 6.05 & .62 \\
\hline \multirow{5}{*}{ Analysis } & $\mathrm{I} 4$ & .86 & .38 & & .14 \\
\hline & I10 & .89 & .68 & 16.19 & .11 \\
\hline & I11 & .78 & .47 & 12.48 & .22 \\
\hline & $\mathrm{I} 13$ & .82 & .43 & 13.29 & .18 \\
\hline & $\mathrm{I} 15$ & .59 & .82 & 8.48 & .41 \\
\hline
\end{tabular}

During the second-level confirmatory factor analysis, the $t$ values of the $\mathrm{m} 6, \mathrm{~m} 20$ and $\mathrm{m} 4$ items, which were determined as reference variables, were not shared. In the CFA measurement model, firstly t values were checked and no item was removed from the scale because $t$ values of all items of the scale were significant at the level of ".01" because they exceeded the limit of 2.56. It was determined that the error variances of the items were between .33 and .89 and all standardized error loads were greater than ".30" and less than ".90". Therefore, it was observed that the error loads were significant at the ".50" level and 
116

S. Y1ldırım Döner, \& S. Demir / Pamukkale University Journal of Education, 54, 99-129, 2022

no item was removed from the scale. It was observed that the variability related to the dialectical thinking factor was mostly explained by the observed variable i7, the least observed variable i1, the variability of the disposition factor being the most observed variable i20, the least i18 observed, and the analysis factor variance explained mostly by the observed variable i15, and the least by the observed variable i3.

Table 8. Second level CFA result correction indexes for scale

\begin{tabular}{|c|c|c|c|c|}
\hline & $\begin{array}{l}\text { Associated } \\
\text { Items }\end{array}$ & $\begin{array}{l}\text { Associated } \\
\text { Variables }\end{array}$ & $\begin{array}{l}\text { Decrease in Chi- } \\
\text { Square Value }\end{array}$ & $\begin{array}{c}\text { New } \\
\text { Estimate }\end{array}$ \\
\hline \multirow{5}{*}{$\begin{array}{l}\text { Part One Correction } \\
\text { Indexes }\end{array}$} & I6 & Disposition & 8.6 & -.15 \\
\hline & I10 & Disposition & 13.0 & .28 \\
\hline & I12 & Disposition & 12.7 & .19 \\
\hline & I15 & Disposition & 14.9 & -.30 \\
\hline & I16 & Disposition & 8.5 & .16 \\
\hline \multirow{10}{*}{$\begin{array}{l}\text { Second Part Correction } \\
\text { Indexes }\end{array}$} & I2 & I1 & 21.7 & .15 \\
\hline & I4 & I1 & 18.4 & .13 \\
\hline & I6 & I3 & 19.5 & .14 \\
\hline & I6 & I5 & 11.7 & -.11 \\
\hline & I9 & $\mathrm{I} 2$ & 11.8 & -.11 \\
\hline & I10 & I4 & 8.8 & .10 \\
\hline & I11 & I6 & 26.0 & .17 \\
\hline & I11 & I10 & 15.0 & .15 \\
\hline & I12 & $\mathrm{I} 3$ & 13.3 & -.11 \\
\hline & I12 & $\mathrm{I} 4$ & 15.2 & .11 \\
\hline
\end{tabular}




\begin{tabular}{|c|c|c|c|}
\hline $\begin{array}{l}\text { Associated } \\
\text { Items }\end{array}$ & $\begin{array}{l}\text { Associated } \\
\text { Variables }\end{array}$ & $\begin{array}{c}\text { Decrease in Chi- } \\
\text { Square Value }\end{array}$ & $\begin{array}{c}\text { New } \\
\text { Estimate }\end{array}$ \\
\hline I13 & I5 & 11.2 & -.10 \\
\hline I13 & I6 & 11.2 & .09 \\
\hline I13 & I11 & 12.3 & -.11 \\
\hline I14 & I3 & 20.5 & .14 \\
\hline I14 & I4 & 9.7 & -.08 \\
\hline I14 & I10 & 12.8 & -.12 \\
\hline I14 & I1 1 & 8.4 & -.09 \\
\hline I15 & I5 & 8.4 & .09 \\
\hline I15 & I1 1 & 8.2 & .13 \\
\hline I15 & I14 & 9.0 & .09 \\
\hline I17 & I14 & 15.2 & .11 \\
\hline I17 & I16 & 13.4 & -.11 \\
\hline I18 & I7 & 10.4 & .08 \\
\hline I18 & I10 & 16.7 & .13 \\
\hline I18 & I13 & 9.4 & -.08 \\
\hline I19 & I7 & 13.2 & .08 \\
\hline I19 & I17 & 14.7 & .09 \\
\hline I20 & I7 & 10.2 & -.06 \\
\hline I20 & I12 & 16.0 & .09 \\
\hline
\end{tabular}




\begin{tabular}{ccccc}
\hline $\begin{array}{c}\text { Associated } \\
\text { Items }\end{array}$ & $\begin{array}{c}\text { Associated } \\
\text { Variables }\end{array}$ & $\begin{array}{c}\text { Decrease in Chi- } \\
\text { Square Value }\end{array}$ & $\begin{array}{c}\text { New } \\
\text { Estimate }\end{array}$ \\
I20 & I17 & 8.7 & -.06 \\
I21 & I4 & 9.8 & -.08 \\
I21 & I6 & 11.1 & -.08 \\
I21 & I7 & 17.3 & -.09 \\
I21 & I10 & 10.4 & -.09 \\
I21 & I14 & 14.3 & .09 \\
I21 & I18 & 13.8 & .09 \\
\hline
\end{tabular}

The correction indexes in the first part were not carried out because they were not found suitable for the structure of the developed scale. Among the different factors, among the second part correction indexes, the researchers did not realize that they were worried that they would disrupt the structure of the scale. Apart from these, the covariance assignment was made for the correction proposal between i4 and i13 (with 146.4 contributions to $\mathrm{X}^{2}$ ), i2 and i3 (with 39.8 contributions to $\mathrm{X}^{2}$ ), which are included in the correction indexes section of the second part and contribute to $\mathrm{X}^{2}$. The covariance assignment for the other modification proposals was not performed since the $\mathrm{X}^{2} / \mathrm{sd}$ value was between 1.875 and 0 and 2, the RMSEA value was between .042 and .00 and .05, and the AGFI value was between .85 and .85 and .90 after the necessary modification was made. However, it was seen that the p-value maintained its significance at the level of .00000 and .01. However, the difference between the expected covariance matrix and the observed covariance matrices, that is, the p-value (.00000), which shows the significance of the $\mathrm{X}^{2}$ value, should not be significant at the .01 level. However, this situation, which can be explained by the size of the sample $(n=506)$, was not performed because other fit indexes were extremely good and sample reduction would be subject to data manipulation, and other fit indexes were also taken into account (Çokluk et al., 2018). 


\begin{tabular}{ccc}
\hline Fit Measures & Value & Fit \\
\hline$X^{2}$ & 345.18 & p >.05 \\
X $^{2} / \mathrm{sd}$ & 1.875 & Perfect Fit \\
AGFI & .85 & Good Fit \\
GFI & .88 & Good Fit \\
CFI & .99 & Perfect Fit \\
NFI & .97 & Perfect Fit \\
NNFI (TLI) & .98 & Perfect Fit \\
RFI & .96 & Perfect Fit \\
IFI & .99 & Perfect Fit \\
RMSEA & .042 & Perfect Fit \\
SRMR & .059 & Good Fit \\
PNFI & .85 & Good Fit \\
PGFI & .70 & Good Fit \\
\hline
\end{tabular}

When the fit indexes of the model were examined as a result of the CFA, it was seen that the $\mathrm{X}^{2}$ value was greater than .05 with "345.18," and it was not significant in this respect. In this respect, it can be said that the model has a good fit. In confirmatory factor analyzes where the sample size is important, degrees of freedom (df) and chi-square $\left(\mathrm{X}^{2}\right)$ values should be taken into account to control model fit (Çokluk, Şekercioğlu, Büyüköztürk, 2012, pp.267-268). In this case, the fact that the value obtained by dividing the chi-square value $\left(\mathrm{X}^{2}\right)$ by the degrees of freedom $\left(\mathrm{X}^{2} / \mathrm{df}=1.875\right)$ is between 0 and 2 indicates the perfect fit in terms of the model (Hoe, 2008 and Şimşek, as cited in 2007, İlhan \& Çetin, 2014). In addition, it can be said that the model's CFI, NFI, NNFI (TLI), RFI, IFI, RMSEA values indicate perfect fit in terms of the model, while AGFI, GFI, SRMR, PNFI, and PGFI values indicate acceptable/good fit (Sümer, 2000, p. 68; Brown acted in 2016. Çokluk, Şekercioğlu, Büyüköztürk, 2012). As a result of the correction procedures carried out within the scope of CFA analysis, it can be stated that the model fit of the Critical Thinking 
Disposition Scale for students at the 5th, 6th, 7th, and 8th-grade students with three factors with 21 items is acceptable, and the scale structure is confirmed in terms of the second level CFA.

Table 10. Correlation values between extrinsic latent variables of the scale

\begin{tabular}{lcccc}
\hline & $\begin{array}{c}\text { Dialectical } \\
\text { Thinking }\end{array}$ & Disposition & Analysis & $\begin{array}{c}\text { Critical Thinking } \\
\text { Disposition }\end{array}$ \\
\hline Dialectical Thinking & 1.00 & & & \\
Disposition & .40 & 1.00 & & \\
Analysis & .59 & .40 & 1.00 & .00 \\
Critical Thinking Disposition & .75 & .84 & .78 & 1.00 \\
\hline
\end{tabular}

As a result of the second level CFA analysis, it was seen that there was a moderate relationship between the internal latent variables of the scale ( $r>.30)$. In addition, it was observed that there was a very strong $(r>.70)$ relationship between the external latent variable and the internal latent variables. In order to test the structural reliability of the Critical Thinking Disposition Scale, each latent variable has been considered as a measurement model, and the structural reliability of these variables was calculated with the formula "structure reliability $=($ standardized loads sum $) 2 /($ standardized loads sum) $2+$ (measurement errors sum of observed variables)" (Çelik and Y1lmaz, 2016, p. 152). As a result of the calculations performed, the structural reliability of the dialectical thinking sub-dimension was calculated as .88 , the disposition sub-dimension as .88 , the analysis subdimension as .66, and for the overall scale, it was calculated as .93. In this context, it can be stated that the structure reliability values of the first two sub-dimensions and the scale, in general, are greater than .70, that the structure reliability is provided for the scale, except for the analysis sub-dimension. The other value to be considered in the CFA process is the explained variance to be calculated with the formula "explained variance $=($ sum of squares of standardized loads) / (sum of squares of standardized loads) + (sum of measurement errors of observed variables)" (Çelik \& Y1lmaz, 2016, p.152). As a result of the calculations made using the formula for the explained variance measurement values of each latent variable of the Critical Thinking Disposition Scale, dialectical thinking internal latent variable .38 , disposition latent variable .64, analysis latent variable .30 , and .41 for the overall scale were found. While the variance values explained were expected to be greater 
S. Yıldırım Döner, \& S. Demir / Pamukkale University Journal of Education, 54, 99-129, 2022

than .50 , it was determined that the other two sub-dimensions and the overall scale were below this value, except for the disposition sub-dimension of the scale. In addition, it can be said that the model fit of the scale is confirmed since both the structural reliability of the scale is good and especially the fit indexes and other parameters are quite good. The path diagram obtained as a result of the modification processes carried out for the Critical Thinking Disposition Scale is as follows:

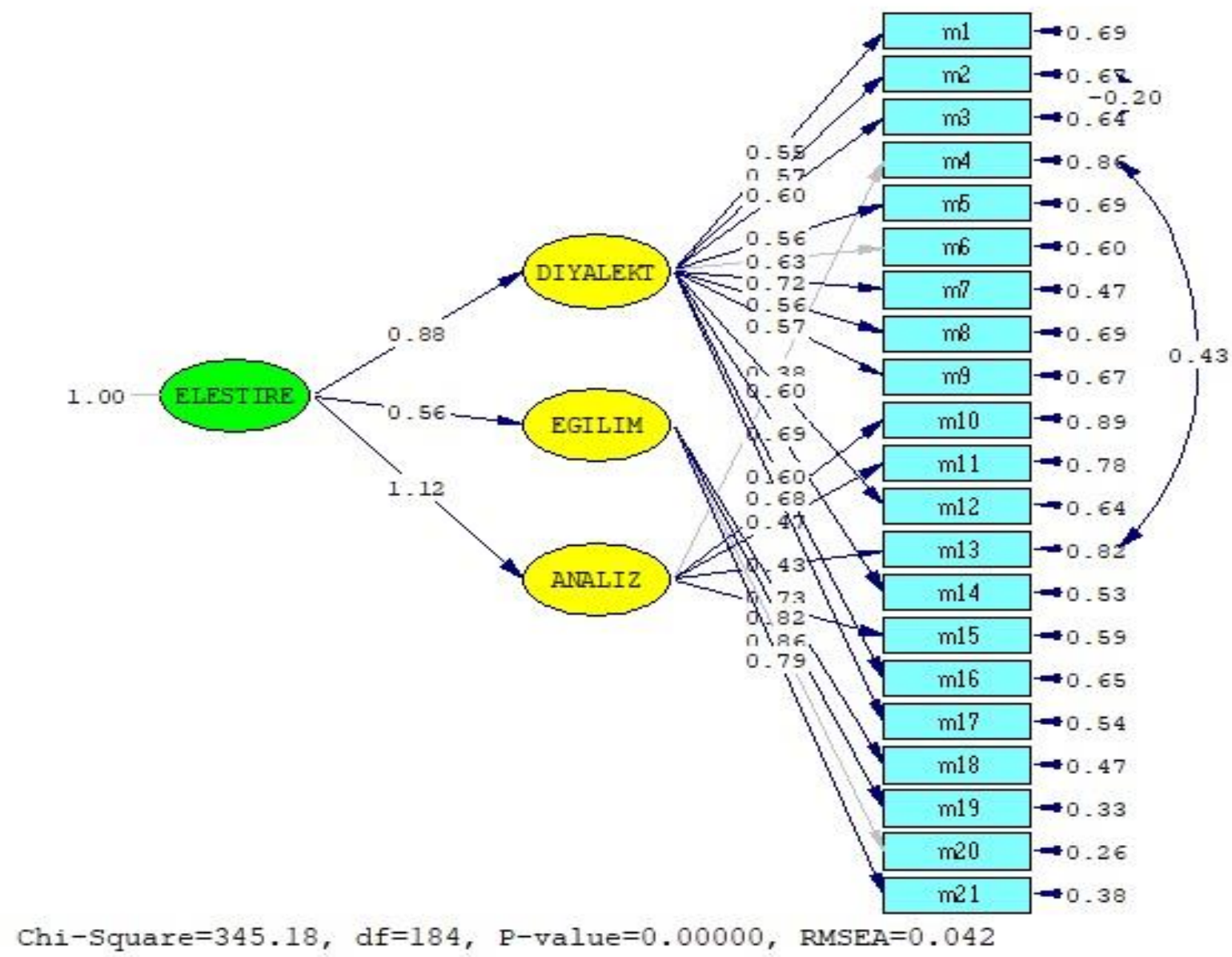

Figure 3. The path diagram was obtained after the modification processes for the Critical Thinking Disposition Scale.

Necessary modifications were made in line with the recommendations within the scope of the second level CFA, which was carried out using the LISREL program, and the scale was finalized. Accordingly, it can be said that it is a 3-dimensional scale model fit with 21 items in total; 12 items, including i1, i2, i3, i5, i6, i7, i8, i9, i12, i14, i16, i17 in the dialectical sub-dimension of the scale, four items in the disposition sub-dimension, including $\mathrm{i} 18, \mathrm{i} 19, \mathrm{i} 20, \mathrm{i} 21$ and five items in the analysis sub-dimension, including i4, i10, i11, i13, 
i15. At the same time, due to the second level CFA, the general score of the scale can be said to be used in analyzes.

\section{Discussion and Conclusion}

In the study, a valid and reliable Middle School Students' Critical Thinking Disposition Scale was developed to determine the critical thinking disposition levels of middle school students (9-14 years old). Critical thinking disposition is a necessary element for realizing critical thinking and the use of skills (Walker, 2003). Skills can become blunt as they cannot be used when there is no disposition. In this respect, it can be stated that teaching the skill alone will not be enough, and the important thing is to create a disposition in the individual or to encourage the desire to use the skill by supporting the existing disposition (Halpern, 1998). For this reason, determining the critical thinking disposition levels and following a path accordingly is important for students and a healthy educational process. Considering that the secondary school level is a transition stage from primary education to secondary education, it can be interpreted that it is important to bring the student to a good level in terms of thinking skills and to make due diligence in this period. In this regard, since a critical thinking disposition scale developed with a sample of secondary school students could not be detected in the literature, the scale was conducted for secondary school students. While developing the scale, the related literature was scanned, and an item pool of 45 items was created based on this. Eight academicians examined the pool of created items from the field of Turkish education and educational sciences within the scope of the Lawsche technique, and as a result of expert item evaluations, the items' CGO value was found to be 78 (Yurdugül, 2005). After making the necessary corrections of the scale, an application was carried out for EFA on 504 students in the 5th-8th secondary school grades. As a result of this analysis, the Critical Thinking Disposition Scale, which has three subdimensions called dialectical thinking, disposition and analysis, was formed. Factor analysis, which combines variables into descriptive categories, is important to reach an underlying concept and facilitate interpretation (Yong \& Pearce, 2013). In the Cronbach Alpha, Spearman-Brown, and Guttman split-half tests, it was concluded that the scale was quite reliable. To test the reliability of the scale, test-retest was applied to 90 students between 5 th and 8th grades of secondary school. In the analysis performed as a result of this application, it was determined that the internal consistency coefficient of the scale was at a good level. Accordingly, it can be said that the Critical Thinking Disposition Scale has sufficient internal consistency. After that, CFA was performed to determine whether the scale was 
verified as a model and to test the hypotheses based on factor analysis. CFA is a kind of structural equation model that deals with measurement models, measures the relationships between observed measurements and latent variables, and is used in the scale development process to examine the latent structure of a test tool and to verify the item-factor relationship model (Brown \& Moore, 2012). In this direction, CFA was conducted with 506 middle school students over a different sample (Çokluk et al.2018, p.275). As a result of this process carried out with different sample groups, it was confirmed that the scale has a threefactor structure, and the scale was finalized. Therefore, it can be stated that the Critical Thinking Disposition Scale for secondary school students is a Likert-type reliable and valid measurement tool that can be used in field studies to determine students' critical thinking dispositions.

\section{Thanks and Information}

This research was created based on the master's thesis titled " The Relationship Between Middle School Students' Critical Thinking Disposition and Reading Skills " carried out in the Turkish Education Department of the Institute of Educational Sciences of Firat University and completed in December 2020. I would like to thank my esteemed mentor, Assoc. Prof. Sezgin DEMIR who contributed throughout the research process.

Ethical Approval: This research was conducted with the permission obtained by the ethics committee of Firat University Institute of Educational Sciences, dated 17/10/2019, number 97132852.

Conflict Interest: There is no conflict of interest to be declared by the authors.

Author Contribution: The first author, Seyhan YILDIRIM DONER, has contributed to the work at the stages of the determination of the problem situation, literature review, data collection and analysis, discussion and reporting of the article; second author Assoc. Prof. Sezgin DEMIR has contributed to the work at the stages of determining the problem situation, determining the research method, collecting and analyzing the data, and reporting and editing the article before submission. 


\section{References}

Akarsu, B. (2019). Eleştirel düşünme sanatı. İstanbul: Cinius Yayınları.

Akın, A., Hamedoğlu, M. A., Arslan, S., Akın, U., Çelik, E., Kaya, Ç. and Arslan, N. (2015). The adaptation and validation of the Turkish version of the critical thinking disposition scale. The International Journal of Educational Researchers, 6(1), 31-35. https://ijer.penpublishing.net/makale indir/82

Allahverdi, K. (2009). John Dewey'de eleştirel düşünme yaklaşımı. Yayımlanmamış yüksek lisans tezi. On Sekiz Mart Üniversitesi Sosyal Bilimler Enstitüsü, Çanakkale.

Ay, Ş. ve Akgöl, H . (2008). Eleştirel düşünme gücü ile cinsiyet, yaş ve sinıf düzeyi. Kuramsal Eğitimbilim Dergisi, 1(2), 65-75. Retrieved from https://dergipark.org.tr/en/pub/akukeg/issue/29373/314325

Aybek, B. (2007). Eleştirel düşünmenin öğretiminde öğretmenin rolü. Bilim, Eğitim ve Düşünce Dergisi,7(2). $\quad$ https://docplayer.biz.tr/34954018-Elestirel-dusunmeninogretiminde-ogretmenin-rolu.html

Brown, T. A. and Moore, M. T. (2012). Confirmatory factor analysis. Handbook of structural equation modeling, 361-379.

Can, A. (2018). SPSS ile bilimsel araştırma sürecinde nicel veri analizi. Ankara: Pegem Akademi.

Cüceloglu, D. (2001). İyi düşün doğru karar ver. İstanbul: Sistem Yayıncılık.

Creswell, J. W. (2017). Eğitim araştırmaları: nicel ve nitel araştırmanın planlanması, yürütülmesi ve değerlendirilmesi. (Çev. Edt. Halil Ekşi). İstanbul: EDAM.

Çokluk, Ö., Şekercioğlu, G. ve Büyüköztürk, Ş. (2016). Sosyal bilimler için çok değişkenli istatistik: SPSS ve LISREL uygulamalart. Ankara: Pegem Akademi.

Demir, S. (2019). Dil edinim ve öğretim kuramları ile ilgili temel kavramlar, (Edt. Halit Karatay), Dil eğitiminin temel kavramları. Ankara: Asos Yayınları, s. 261-284.

Demircioğlu, E. (2012). Eleştirel düşünme eğilimi ölçeği'nin uyarlama çalışması ve faktör yapısının farklı değişkenlere göre incelenmesi. Yayımlanmamış yüksek lisans tezi, Abant İzzet Baysal Üniversitesi Eğitim Bilimleri Enstitüsü, Bolu. 
Dilekli, Y. (2019). What are the dimensions of thinking skills in Turkish literature?: A content analysis study. International Journal of Evaluation and Research in Education, 8(1), 110-118. https://files.eric.ed.gov/fulltext/EJ1211267.pdf

Eşel, E. (2005). Kadın ve erkek beyninin farklılıkları. Klinik Psikofarmakoloji Bülteni, 15(3). http://www.psikofarmakoloji.org/pdf/15_3_7.pdf

Facione, P. A. (1990). Critical thinking: A statement of expert consensus for purposes of educational assessment and instruction-The Delphi report. Millbrae, CA: California Academic Press. https://eric.ed.gov/?id=ED315423

Facione, P., Giancarlo, C., Facione, N. and Gainen, J. (1995). The disposition toward critical thinking. Journal of General Education, 44(1), 1-25. DOI: 10.22329/il.v20i1.2254

Fahim, M. and Eslamdoost, S. (2014). Critical thinking: Frameworks and models for teaching. English Language Teaching, 7(7), p141. https://doi.org/10.5539/elt.v7n7p141

Gliem, J. A. and Gliem, R. R. (2003). Calculating, interpreting, and reporting Cronbach's alpha reliability coefficient for Likert-type scales. Midwest Research-to-Practice Conference in Adult, Continuing, and Community Education. http://hdl.handle.net/1805/344

Halpern, D. F. (1998). Teaching critical thinking for transfer across domains: Disposition, skills, structure training, and metacognitive monitoring. American Psychologist, 53(4), 449-455. doi:10.1037/0003-066x.53.4.449

İlhan, M. ve Çetin, B. (2014). LISREL ve AMOS Programları Kullanılarak Gerçekleştirilen Yapısal Eşitlik Modeli (YEM) Analizlerine İlişkin Sonuçların Karşılaştırılması. Eğitimde ve Psikolojide Ölçme ve Değerlendirme Dergisi, 5(2), Kış 2014, 26-42. Journal of Measurement and Evaluation in Education and Psychology, 5(2), Winter 2014, 26-42.

Kılıç, H. E. ve Şen, A. İ. (2014). UF/EMI eleştirel düşünme eğilimi ölçeğini Türkçeye uyarlama çalışması. Eğitim ve Bilim, 39(176), 1-12. http://dx.doi.org/10.15390/EB.2014.3632

Kökdemir, D. (2003). Belirsizlik durumlarında karar verme ve problem çözme. Yayımlanmamış doktora tezi, Ankara Üniversitesi Sosyal Bilimler Enstitüsü, Ankara. 
Kökdemir, D. (2012). Üniversite eğitimi ve eleştirel düşünme. PiVOLKA, 21(7), 16-19. https://www.elyadal.org/pivolka/21/PiVOLKA_21_06.pdf

Kurnaz, A. (2007). İlköğretim beşinci sınıf sosyal bilgiler dersinde beceri ve içerik temelli eleştirel düşünme ögrretiminin ögrrencilerin eleştirel düşünme becerileri, erişi ve tutumlarına etkisi. Yayımlanmamış doktora tezi. Selçuk Üniversitesi Sosyal Bilimler Enstitüsü, Konya.

Lawshe, C. H. (1975). A quantitative approach to content validity. Personel Psychology. 28, 563-575. DOI=10.1.1.460.9380

Perkins, D., Jay, E. and Tishman, S. (1993). Beyond abilities: A dispositional theory of $\begin{array}{llll}\text { thinking. } & \text { The }\end{array}$ https://eric.ed.gov/?id=EJ456333

Piaget, J. (2019). Çocuk psikolojisi. İstanbul: Pinhan Yayıncılık.

Semerci, N. (2016). Eleştirel düşünme eğilimi (EDE) ölçeğinin geliştirilmesi: Geçerlik ve güvenirlik revize çalışması. Turkish Studies, $11(9), \quad$ 725-740. http://dx.doi.org/10.7827/TurkishStudies.9573

Sönmez, V. ve Alacapınar, F. (2017). Örneklendirilmiş bilimsel araştırma yöntemleri. Ankara: Anı Yayıncılık.

Sümer, N. (2000). Yapısal eşitlik modelleri: temel kavramlar ve örnek uygulamalar. Türk Psikoloji Yazılarl, 3(6), 49-73

Şencan, H. (2005). Sosyal ve davranışsal ölçümlerde geçerlilik ve güvenirlik. Ankara: Seçkin Matbaası.

Tümkaya S. ve Aybek B. (2008). Üniversite öğrencilerinin eleştirel düşünme eğilimlerinin sosyo- demografik özellikler açısından incelenmesi. Çukurova Üniversitesi Sosyal Bilimler Enstitüsü Dergisi, 17(2), 387-402. Retrieved from https://dergipark.org.tr/tr/pub/cusosbil/issue/4379/60056

Walker, S. E. (2003). Active learning strategies to promote critical thinking. Journal of $\begin{array}{llll}\text { athletic } & \text { training, } & 38(3), & \end{array}$ https://www.ncbi.nlm.nih.gov/pmc/articles/PMC233182/ 
S. Yıldırım Döner, \& S. Demir / Pamukkale University Journal of Education, 54, 99-129, 2022

Yong, A. G. and Pearce, S. (2013). A beginner's guide to factor analysis: Focusing on exploratory factor analysis. Tutorials in quantitative methods for psychology, 9(2), 79-94.

Yurdugül, H. (2005). Ölçek geliştirme çalışmalarında kapsam geçerliği için kapsam geçerlik indekslerinin kullanılması. XIV. Ulusal Eğitim Bilimleri Kongresi, 1, 771-774.

Zhang, L. F. (2003). Contributions of thinking styles to critical thinking dispositions. The Journal of Psychology, 137(6), 517-544. DOI: 10.1080/00223980309600633 